\title{
Generation of the Cape Ghir upwelling filament: A numerical study
}

\author{
C. Troupin ${ }^{\mathrm{a}, *}$, E. Mason ${ }^{\mathrm{b}}$, J.-M. Beckers ${ }^{\mathrm{a}}$, P. Sangràc \\ ${ }^{a}$ Université de Liège, GHER-MARE, AGO, Allée du 6-Août, 17, Sart-Tilman B5a, B4000 Liège, Belgium \\ ${ }^{b}$ Departament d'Oceanografia Física, Institut de Ciències del Mar-CSIC, Barcelona, Spain \\ ${ }^{c}$ Facultad de Ciencias del Mar, Edificio Ciencias Básicas, Universidad de Las Palmas de Gran Canaria, 35017 Las Palmas de Gran Canaria, Spain
}

\begin{abstract}
Filaments are narrow, shallow structures of cool water originating from the coast. They are typical features of the four main eastern boundary upwelling systems (EBUS). In spite of their significant biological and chemical roles, through the offshore exportation of nutrient-rich waters, the physical processes that generate them are still not completely understood. This paper is a process-oriented study of filament generation mechanisms. Our goal is twofold: firstly, to obtain a numerical solution able to correctly represent the characteristics of the filament off Cape Ghir (30³8'N, northwest Africa) in the Canary EBUS and secondly, to explain its formation by a simple mechanism based on the balance of potential vorticity.

The first goal is achieved by the use of the ROMS model (Regional Ocean Modeling System) with embedded domains around Cape Ghir, with a horizontal resolution going up to $1.5 \mathrm{~km}$ for the finest domain. The latter gets its initial and boundary conditions from a parent solution and is forced by climatological, high-resolution atmospheric fields. The modeled filaments display spatial, temporal and physical characteristics in agreement with the available in situ and satellite observations. This model solution is used as a reference to compare the results with a set of process-oriented experiments. These experiments allow us to reach the second objective. The solutions serve to highlight the contributions of various processes to the filament generation. Since the study is focused on general processes present under climatological forcing conditions, inter-annual forcing is not necessary.

The underlying idea for the filament generation is the balance of potential vorticity in the Canary EBUS: the upwelling jet is characterized by negative relative vorticity and flows southward along a narrow band of uniform potential vorticity. In the vicinity of the cape, an injection of relative vorticity induced by the wind breaks the existing vorticity balance. The upwelling jet is prevented from continuing its way southward and has to turn offshore to follow lines of equal potential vorticity.

The model results highlight the essential role of wind, associated with the particular topography (coastline and bottom) around the cape. The mechanism presented here is general and thus can be applied to other EBUS.
\end{abstract}

Keywords: Eastern boundary, Canary Upwelling system, Upwelling filaments, Potential vorticity, ROMS model PACS: 92.30.Vn, 92.10.ak, 92.10.Ty

\section{Introduction}

The Eastern Boundary Upwelling Systems (EBUS) constitute high-productivity regions of the world ocean (e.g, Ryther, 1969; Durand et al., 1998; Jennings et al., 2001). They are driven by large-scale wind patterns responsible for coastal upwelling, resulting in the increase of nutrient concentration in the surface layers. Sea Surface Temperature (SST) images covering the EBUS reveal the presence of narrow $(O(10 \mathrm{~km}))$, elongated $(O(100 \mathrm{~km}))$ structures of cool water extending seaward in the upper surface layer $(O(100 \mathrm{~m}))$, preferentially located near to coastal irregularities. These structures are called "upwelling filaments", or simply "filaments". Associated with the low temperature signal, high-chlorophyll concentrations are frequently observed through satellite imagery, bearing the important biological activity of filaments.

\footnotetext{
${ }^{*}$ Corresponding author. Tel.:+32 43662340

Email addresses: ctroupin@ulg.ac.be (C. Troupin), emason@icm.csic.es (E. Mason), JM. Beckers@ulg. ac . be (J.-M. Beckers), psangra@dfis.ulpgc.es (P. Sangrà)
}

Filaments were first observed during the late 1970-early 1980's in the California Current System (CCS) through in situ measurements (e.g., Brink, 1983; Brink et al., 1984; Mooers and Robinson, 1984) and remote sensing imagery (e.g., Bernstein et al., 1977; Ikeda and Emery, 1984; Flament, 1985). Intensive surveys were carried out during multidisciplinary projects in the CCS: the Coastal Ocean Dynamics Experiment (CODE, Kosro and Huyer, 1986; Beardsley and Lentz, 1987), the Coastal Transition Zone program (CTZ, Brink and Cowles, 1991; Strub et al., 1991) and the Eastern Boundary Current experiment (EBC, Huyer et al., 1998).

Numerous cruises also took place in the Canary Upwelling system (CUS), with the objective of examining the dynamics of the filaments and studying their effects upon primary production (e.g., Haynes et al., 1993; Hagen et al., 1996; Barton et al., 1998; Barton and Arístegui, 2004; Pelegrí et al., 2005). Remote-sensing imagery helped to identify the sites favorable to filaments (e.g, Van Camp et al., 1991; García-Weill et al., 1994; Kostianoy and Zatsepin, 1996; Hernández-Guerra and Nykjaer, 1997). 
Different mechanisms have been proposed for the filament generation: interaction of the upwelling jet with the topography (Ikeda and Emery, 1984; Strub et al., 1991; Hagen et al., 1996), baroclinic instability (Ikeda and Emery, 1984), meandering of the equatorward jet (Strub et al., 1991), interaction with a field of synoptic-mesoscale eddies (Mooers and Robinson, 1984; Lutjeharms et al., 1991; Strub et al., 1991; Peliz et al., 2004), influence of the wind (e.g., Kelly, 1986; Hagen et al., 1996; Castelao and Barth, 2007). Pelegrí et al. (2005) proposed that an injection of positive vorticity due to the friction of the flow with the sea floor created the offshore deflection of the jet. Most of the surveys point at coastline or topography irregularities as a responsible factor. Indeed, along the coast of NW Africa, numerous capes (Fig. 1) are frequently affected by filaments: Cape Ghir (Hagen et al., 1996; Pelegrí et al., 2005), Cape Jubi, Cape Bojador and Cape Blanc (Gabric et al., 1993; Karakas et al., 2006).

The combination of high spatial resolution (to capture the filaments) and large domain extension (to reproduce the largescale oceanic features) required by the filament modeling often implies the use of nesting procedures. Several models have been implemented in the Canary EBUS. Spall (1990) used an eddy-resolving model covering the Canary basin to study the local circulation. With a horizontal resolution close to $35 \mathrm{~km}$, the model could reproduce the main currents. The authors reported problems in the eddy kinetic energy values and in the representation of the Mediterranean water tongue, probably related to the specification of the open boundary conditions. Johnson and Stevens (2000) used a $1 / 6^{\circ}$-resolution model in a region extending from the north of Portugal to the south of Canary Islands, including the Azores Archipelago and the Strait of Gibraltar. Their simulations were able to generate the Cape Ghir filament and to show that the filament is stronger during the upwelling maximum. Stevens et al. (2000) applied a similar model to the Iberian shelf-slope region and pointed out the need for a enhanced-resolution implementation in order to be able to model the effects of the capes. With a $1 / 12^{\circ}$-resolution model, Stevens and Johnson (2003) noted that filaments tend to appear at the same locations along the coast: at $25.5^{\circ} \mathrm{N}, 28^{\circ} \mathrm{N}$ (Cape Juby), $31^{\circ} \mathrm{N}$ (Cape Ghir) and $33^{\circ} \mathrm{N}$, in agreement with satellite observations. However, their modeled filaments were too broad and penetrated too far offshore in comparison with observations.

With a $9 \mathrm{~km}$-resolution model forced by seasonal wind, Batteen et al. (2000) studied the effects of the coastline on the eddy and filament structures in the Canary Current system. Despite using a flat bottom (4500 $\mathrm{m}$ depth), they were able to obtain filaments in agreement with field measurements and attached to the main capes. Their experiments underlined the role played by the wind in the generation of filaments and the importance of the coastline to obtain realistic locations. Another processoriented study was conducted by Batteen et al. (2007) in the same area with a terrain-following, $3 \mathrm{~km}$-resolution model. Filament structures were obtained off Cape Ghir when an iterative topography developed by Martinho and Batteen (2006) was used, while the Gaussian smoothed topography only generated little mesoscale activity.
The peculiarity of the Cape Ghir region was also highlighted by Mason et al. (2011): in their study of the Canary Current, they showed that its variability was related to the propagation of planetary waves, attributed to a temporal variation of the wind stress curl (e.g., Dickinson, 1978; Hagen, 2005), in particular between Cape Sim and Cape Ghir. Another important conclusion from their work is that the Canary Current tends to be insensitive to variability in the Azores Current.

The few number of numerical model implementations correctly simulating the Cape Ghir filament and the lack of understanding of the mechanism motivated us to employ a highresolution numerical model around Cape Ghir, as described in Section 2. A mechanism based on the conservation of potential vorticity (PV) is proposed in Section 3. Several processoriented numerical experiments (Section 4) are conducted in order to assess the role of various factors in the frame of the PV balance. Conclusions and future work are developed in Section 5.

\section{Filament numerical model}

The Regional Ocean Model System (ROMS, UCLA version, Shchepetkin and McWilliams, 2005, 2009) is used in order to simulate the Cape Ghir filament and to support the filament generation mechanism (Section 3 ). The solution obtained will be used as the baseline experiment for comparing and discussing the results of the different process-oriented experiments (Section 4).

The weakly diffusive numerical schemes of ROMS allows for the representation of small scale processes that are critical for the generation of filaments. Another argument in favor of ROMS is the implementation existing in the northeast Atlantic Ocean (Mason et al., 2008, 2011).

\subsection{Nested domains}

With the objectives of having a fine spatial resolution of the filament and correctly reproduce the large-scale features, the model is successively run in embedded domains, as depicted in Fig. 1. The solution is progressively downscaled from domain $\mathcal{D}_{1}$ to domain $\mathcal{D}_{3}$ using the one-way off-line nesting method roms2roms (Mason et al., 2010). Their method is designed to reduce unwanted boundary effects, such as spurious currents or wave reflection.

In terms of mesoscale structures such as filaments or eddies, we fully expect these to be passed from parent to child in our configuration. The realism of the dynamics along the boundary in an offline forcing configuration with roms 2 roms depends on factors such as:

- The ratio between parent and child grid resolutions: Blayo and Debreu (2005) suggest that 5 may be the upper limit, ours is 3 .

- The frequency of updates at the boundary: $\mathcal{D}_{3}$ is forced with 3-day averages from $\mathcal{D}_{2}$. This is in line with the experiments of Mason et al. (2010). 
- An optimized open boundary condition: the same code as Mason et al. (2010) was used.

The different domains, summarized in Tab. 1, are as follows:

- In $\mathcal{D}_{1}$ (large domain), a 15 km-resolution North Atlantic solution is produced (Mason et al., 2008). The procedures applied to obtain this solution are identical to those described in Mason et al. (2011), although the choice of the domain and the horizontal resolution slightly differ. This configuration is run for a period of 19 years. The solution corresponding to the last 7 years provides initial and boundary conditions to $\mathcal{D}_{2}$.

- In $\mathcal{D}_{2}$ (intermediate domain), simulations are run at a horizontal resolution of $4.5 \mathrm{~km}$ and for a period of 7 years, in order to reach an equilibrium situation. The last 4 years are used for downscaling to the domain $\mathcal{D}_{3}$. The results are stored as 3-day averages.

- $\mathcal{D}_{3}$ (small domain), simulations are run at a resolution of $1.5 \mathrm{~km}$ during a period of 4 years and the results are stored as 24-hour averages. $\mathcal{D}_{3}$ extends more than $200 \mathrm{~km}$ off the coast. The extension of the domain is intentionally small, so as to to spatially limit the effects of the modifications in the process-oriented experiments (Section 4). In some cases, the filament will not be entirely captured within the domain. However, this does not constitute an issue since we are more concerned by the generation mechanism than the offshore dynamics.

In this work, we will mostly focus on domains $\mathcal{D}_{2}$ and $\mathcal{D}_{3}$.

Table 1: Domain characteristics.

\begin{tabular}{cccc}
\multicolumn{4}{c}{ Table 1: Domain characteristics. } \\
\hline Domain & Grid size & Spatial resolution $(\mathrm{km})$ & Running period (years) \\
\hline $\mathcal{D}_{1}$ & $222 \times 324$ & 15.0 & 19 \\
$\mathcal{D}_{2}$ & $258 \times 290$ & 4.5 & 7 \\
$\mathcal{D}_{3}$ & $162 \times 162$ & 1.5 & 4 \\
\hline
\end{tabular}

\subsection{Atmospheric forcing}

The grid and forcing files (heat fluxes, freshwater fluxes, wind stress) are prepared using the ROMS tools package (Penven et al., 2008). The rivers in the studied area have weak rates of flow and thus are not taken into account in the model. The climatological forcing is preferred to inter-annual forcing, in agreement with the objectives set up in this work.

\subsubsection{Wind}

For the baseline experiment, the Scatterometer Climatology of Ocean Winds (SCOW, Risien and Chelton, 2008) is considered. It consists of climatological monthly-mean wind fields at a $0.25^{\circ}$-resolution.

Summer and winter wind stress fields, along with the mean seasonal cycle, are shown in Fig. 2 in a limited region around Cape Ghir. Between Cape Ghir and Cape Sim, wind intensity is increased, both in summer and winter, probably under the influence of the High Atlas range, a west-east oriented mountain range located in Morocco (see Fig. 1). As the wind direction is principally equatorward, its intensification results in a larger Ekman transport and therefore a stronger upwelling. This situation contrasts with other upwelling area, such as the California Current System or the Iberian Peninsula, where winds are poleward in winter, so the upwelling takes place mainly during summer. South of Cape Ghir, a zone of calm winds extends until Cape Jubi. The seasonal cycle (Fig. 2, right panel) is in agreement with the large-scale atmospheric situation: winds are upwelling favorable all year long, but are more intense during summer, because of the northward migration of the Azores High (Wooster et al., 1976).

\subsubsection{Heat flux}

Fields of net heat fluxes are extracted from the 2005 Comprehensive Ocean-Atmosphere Data Set (COADS, Woodruf et al., 1998; Worley et al., 2005). They display an overall southwest gradient (Fig. 3), with maximal values located near the Morocco coasts. In winter, the flux is slightly negative (i.e., from ocean to atmosphere) for most of the domain. During that period, one can expect a convective mixing to take place, leading to a deep mixed layer. In summer, the flux is positive everywhere, with the maximal values $\left(160 \mathrm{~W} / \mathrm{m}^{2}\right)$ taking place just south of Cape Ghir. Due to relief, this area is wind sheltered, as shown in the wind plot of Fig. 2. The seasonal cycle (Fig. 3, right panel) shows the contrast between the April-September and October-March periods. The period of maximum heat flux corresponds to the period of strongest winds. The freshwater balance (not shown) points out a slight dominance of evaporation over precipitation.

\subsection{Bathymetry}

The General Bathymetric Chart of the Oceans (GEBCO, Hunter and Macnab, 2003) provides high-resolution (up to 30 arc-second) bathymetry of the world ocean. For numerical concern, the bathymetry is modified as follows: all the depths lower than a given threshold $\mathrm{h}_{\min }=25 \mathrm{~m}$ are set to this value. The bathymetry is then coarsened to remove the possible sources of aliasing. Finally, a smoothing filter is applied repeatedly on the logarithm of the depth $h$, in order to reduce $r=\|\nabla h\| / h$, the ratio between the depth gradient and the depth, to a value $\mathrm{r}_{\max }=0.20$.

\subsection{Baseline simulation results}

As the solution of this configuration will be used as a reference for further comparisons (Section 4), it is essential to describe its solution and to demonstrate that it is capable to reproduce mesoscale structures similar to those observed in nature. Although the paper is centered on processes, the proper simulation of the upwelling filament constitutes a first achievement. In particular, with the climatological configuration implemented here, it is demonstrated that forcing with multi-year averaged fields is sufficient to generate filaments at the right location and with realistic spatial and temporal dimensions, in agreement with Batteen et al. (2000).

Nevertheless, the role of high-frequency wind variations cannot be discarded: off the Oregon coast, experiments with temporally variable winds (Durski and Allen, 2005), with relaxed 


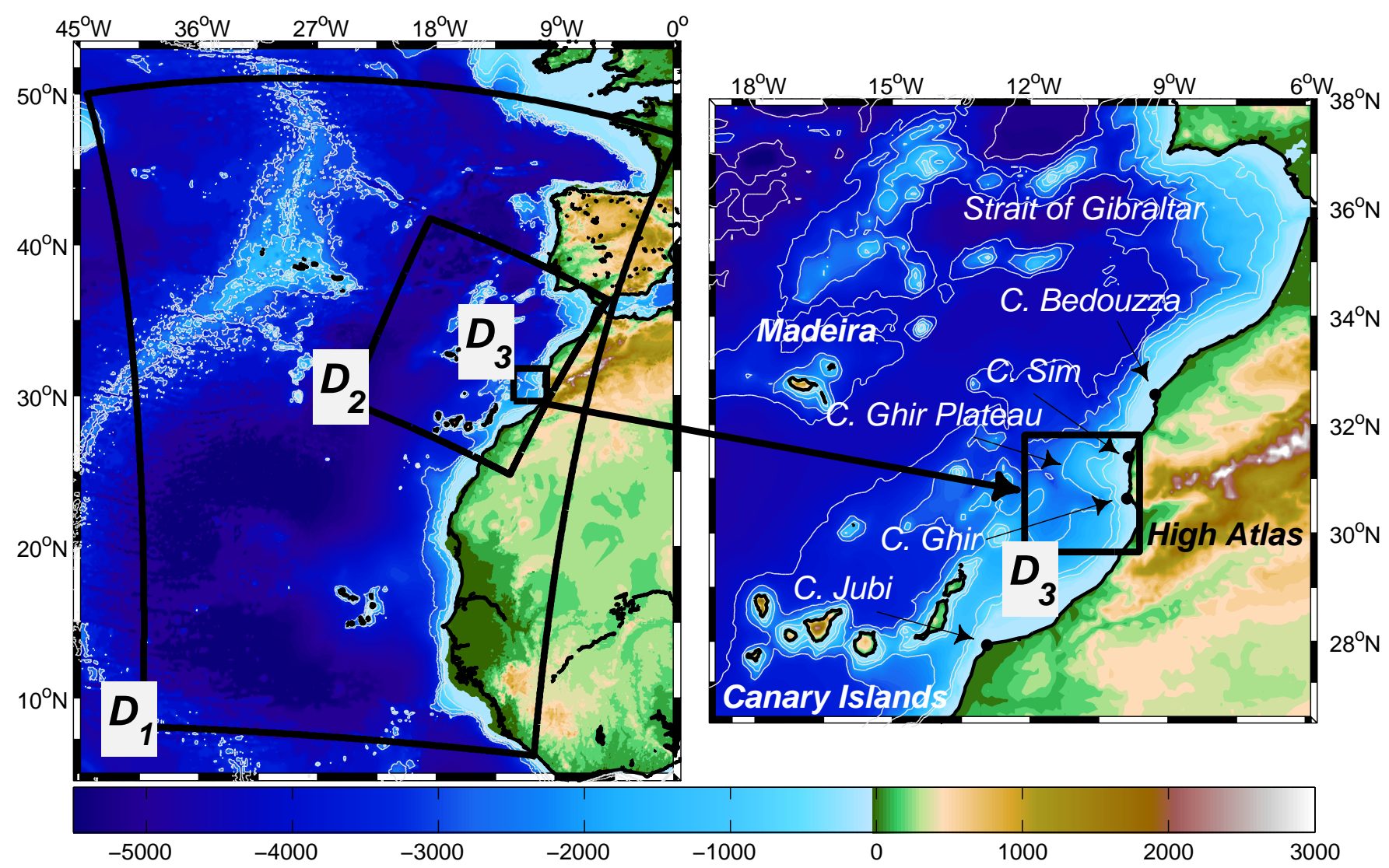

Figure 1: Topography and nested domains (thick black lines) used for the filament modeling, referred to as: the large domain $\mathcal{D}_{1}$, the intermediate domain $\mathcal{D}_{2}$ and the small domain $\mathcal{D}_{3}$. The main topographic features are indicated in the close-up view (right). Isobaths $500,1000,2000$ and $3000 \mathrm{~m}$ (thin white lines) are superimposed on both maps.

and sustained winds (Durski et al., 2007) or with a timeperiodic winds (Durski et al., 2008) underlined their role in the creation of alongshore-scale instabilities and large-scale disturbances in the upwelling front. Experiments with more realistic winds will be performed in a future work.

\subsubsection{Intermediate domain}

In order to match the model horizontal resolution, we extracted satellite images from the Medspiration project database (http://www.medspiration.org): the SST measurements are acquired by the AVHRR sensor with a 2-km spatial resolution. In Fig. 4 a, the model results on domain $\mathcal{D}_{3}$ are overlaid on the $\mathcal{D}_{2}$ for the period 10 to 12 May, while Fig. 4 b compares the $\mathcal{D}_{2}$ solution and satellite SST for the period 4 to 6 September, in both case for the last year of simulation (Fig. 4). The satellite SST is also averaged over these periods, here for the year 2009. The left panel of Fig. 4a demonstrates the compatibility of the solutions in $\mathcal{D}_{2}$ and $\mathcal{D}_{3}$ :

- the coastal upwelling has similar width and temperature across the boundary between the two domains;

- the eddy structure is correctly passed between the child and the parent grids.
From 10 to 12 May, the model produces a broad filament, with a length exceeding $100 \mathrm{~km}$. The coastal upwelling off Africa is weaker in the satellite composite. We attribute this discrepancy to the difference in the wind forcing. Away from the coasts, the model SST appears to be lower than what is observed by satellite. Again, the different atmospheric forcing can be invoked to justify this difference. Moreover, time series of temperature maps (both for satellite and model; not presented here) tend to show that the surface heating is very rapid in May and June.

From 4 to 6 September, the overall distribution of SST in the region is well reproduced by the model. Highest SST values are observed in the southwestern part of the domain and around the Strait of Gibraltar. The upwelling is clearly recognizable as a band of cool water, that extends along the NW Africa coast until $33^{\circ} \mathrm{N}$. The model also reproduces well the Cape Ghir filament location, just north of Cape Ghir. The offshore extension and width of the filament obtained with the model also match well with those of the satellite image. The location where the filament detaches, just north of Cape Ghir, is similar in both cases. The mesoscale structures are well captured by the model, suggesting that the numerical grid choice, the climatological configuration and the forcing implemented here are suitable to simulate the filament. 

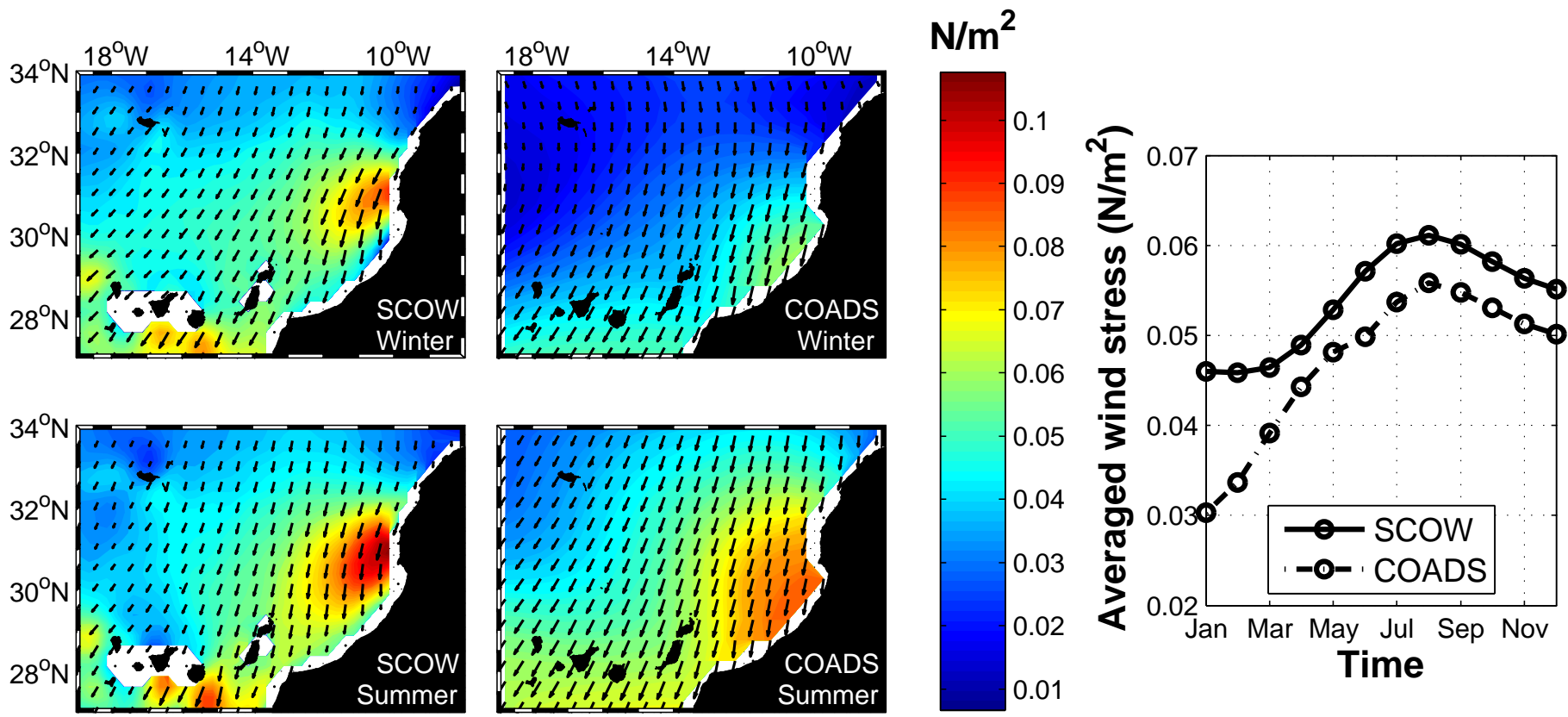

Figure 2: SCOW and COADS wind stress fields in winter (top) and summer (bottom) interpolated on the numerical grid $\mathcal{D}_{3}$. The seasonal cycle (right) is obtained by spatially averaging the wind stress over the domain.

\subsubsection{Small domain}

SST in $\mathcal{D}_{3}$ corresponding to base line model is presented: results are shown as a daily average (Fig. 5a) and as an average over the first two weeks of September (Fig. 5b). The filament structure is identified by a tongue of cool water that propagates offshore, at a latitude slightly higher than that of Cape Ghir, and turns northward around $11^{\circ} 15^{\prime} \mathrm{W}$. It extends about $180 \mathrm{~km}$ offshore, introducing an negative anomaly of $2.5^{\circ} \mathrm{C}$ with respect to the open ocean temperature. The average width is between 10 and $20 \mathrm{~km}$. The maximal velocities are on the order of $0.5 \mathrm{~m} \mathrm{~s}^{-1}$, in agreement with the observations of Hagen et al. (1996) and Pelegrí et al. (2005). The shape of the filament is highly variable. The SST composite constructed from AVHRR measurements (Fig. 5c) confirms that the model results in $\mathcal{D}_{3}$ are plausible.

Time series of model and remote sensed SST (not shown here) indicate that the filament is a quasi-permanent feature, more frequently observed in summer and early fall, when the trade winds and the upwelling peak (e.g., Haynes et al., 1993; Johnson and Stevens, 2000). During these periods, its offshore extension is also maximal and the gradients between filament and non-filament waters are stronger because of the stronger stratification provoked by the intense heat flux. On the contrary, the winter deep mixed layer may reduce the contrast between filament upwelled waters and open ocean waters. The behavior of the mixed layer was examined with the 1-dimension version of the ROMS model, at a location with similar atmospheric conditions (south of the Canary Islands) by Troupin et al. (2010).

It is worth noting the small-scale instabilities taking place on the southern part of the filament, specially visible on the daily field (Fig. 5a). With the multi-year simulations, it was observed that filament location, shape and dimensions are con- sistent from one year to another.

\section{Generation mechanism based on potential vorticity con- servation}

\subsection{Formulation}

The proposed mechanism is developed in the framework of the Ertel's potential vorticity conservation theorem (e.g., Müller, 1995). This theorem states that if the fluid is homogeneous, inviscid, and if no frictional forces are applied, then PV is conserved along streamlines or inversely, the water parcels must flow along constant PV lines. For an homogeneous, rotating fluid Ertel's theorem can be formulated as

$$
\frac{d q}{d t}=\frac{d}{d t} \frac{f+\zeta}{h}=0,
$$

where $q$ is the PV, $f$ the planetary vorticity, $\zeta$ the relative vorticity and $h$ the depth of the water column. Obviously, the aforesaid conditions are not completely fulfilled in our case, but the conservation of PV is a reasonable hypothesis of work if we limit ourselves to the surface layer.

Laiz et al. (2001) studied the drainage of the subtropical gyre by the NW Africa upwelling system. Following the quasigeostrophic dynamics (e.g., Pedlosky, 1987) and Ertel's theorem, they stated that water parcels must flow along a meridional band of homogeneous PV on their way toward the equator through the upwelling jet. Since planetary vorticity decreases equatorward, the relative vorticity of the flow has to increase in order to preserve its PV. The relative vorticity of the jet is negative, therefore its absolute value decreases when going south.

The PV is represented in summer for the large and intermediate domains (Fig. 6), using the baseline configuration (Section 2). It shows that: 


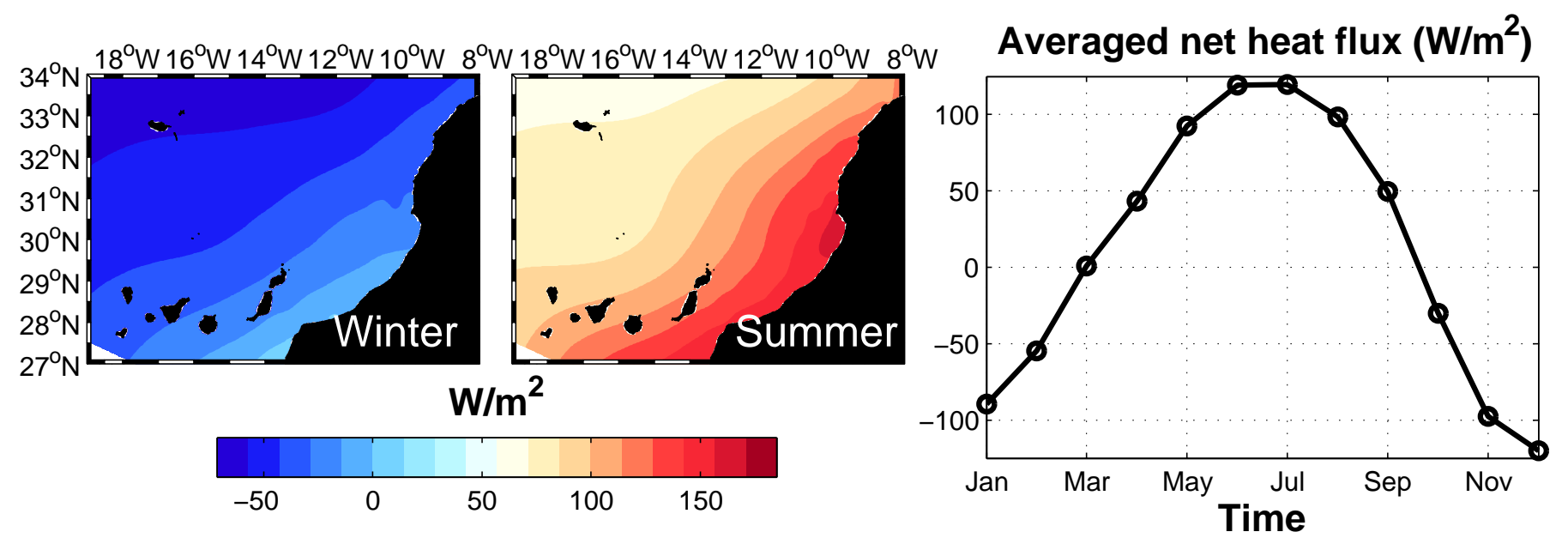

Figure 3: COADS heat fluxes in winter (left), summer (middle) interpolated on the numerical grid and mean seasonal cycle (right).

- The dominance of the planetary vorticity over the relative vorticity outside the coastal area, as evidenced by the structure of the equal-PV lines in the large domain (Fig. 6a).

- The band of lower PV (corresponding to negative relative vorticity) along the African coastline related to the upwelling jet and its overall decrease toward the equator (in particular with the intermediate domain, Fig. 6b).

Laiz et al. (2001) showed that the PV value in the homogeneous meridional band is approximately equal to the value at the point of detachment of the flow, where planetary vorticity is the lowest. For the Canary Current system, the latitude where the current detaches from the coast is close to $20^{\circ} \mathrm{N}$ (e.g., Stramma, 1984; Stramma and Schott, 1999), more than $1000 \mathrm{~km}$ to the south of Cape Ghir.

Now, for the Cape Ghir filament to form, it is assumed that the jet receives an external input of PV, preventing the flow to migrate equatorward along the meridional band of homogeneous PV. In order to accommodate the PV increase, the flow detaches from the coast and propagates offshore, towards higher values of PV.

Going back to formula (1), we notice that $h$, the depth of the water column, has not been taken into account yet. When the jet starts propagating offshore, it has to overcome an augmentation of the depth, from the shelf to the open ocean. It is not the real depth (bathymetry) that has to be considered, but the thickness of the surface layer (see next Section). The consideration of depth can provide an explanation of the preference of the filament to uprise over the Cape Ghir plateau, north of Cape Ghir; there, the shelf is wider, and the motion toward the ocean is made easier.

In summary, the hypothesis of this work is twofold:

1. To be able to migrate southward, water parcels must flow along a meridional band of homogeneous PV, where its value is lower that the corresponding value of the ocean interior, until they reach the latitude of detachment of the flow.

2. A local injection of positive relative vorticity by the wind curl increases locally the PV of the flow, forcing the water parcels to leave the homogeneous band of lower PV and travel westward.

\subsection{Analysis of orders of magnitude}

Before the application of the numerical model, the order of magnitude of the different contributions to the PV are examined. The decrease of planetary vorticity $\Delta f$ due to the southward motion from Cape Ghir to the point of westward turning of the Canary Current (at the latitude of Cape Blanc, e.g., Stramma and Schott, 1999) is easily computed:

$$
\Delta f=2 \Omega\left(\sin \lambda_{\text {C.Ghir. }}-\sin \lambda_{\text {C.Blanc }}\right)=2.25 \times 10^{-5} s^{-1},
$$

where $\Omega$ is the Earth rotation speed and $\lambda$ the latitude. Now, to estimate the relative vorticity imparted by the wind to the flow, a reduced-gravity model forced by a wind stress $\tau$ is used. Such a model fits well to the case of a coastal upwelling, as it permits the capture of the structure within the main thermocline. The equations for the momentum and for the mass conservation read:

$$
\begin{aligned}
\frac{\partial u}{\partial t}+u \frac{\partial u}{\partial x}+v \frac{\partial u}{\partial y}-f v & =-g^{\prime} \frac{\partial h}{\partial x}+\frac{\tau^{x}}{\rho_{0} h} \\
\frac{\partial v}{\partial t}+u \frac{\partial v}{\partial x}+v \frac{\partial v}{\partial y}+f u & =-g^{\prime} \frac{\partial h}{\partial y}+\frac{\tau^{y}}{\rho_{0} h} \\
\frac{\partial h}{\partial t}+\frac{\partial}{\partial x}(h u)+\frac{\partial}{\partial y}(h v) & =0
\end{aligned}
$$

with $h$, the surface layer thickness, $g^{\prime}=\frac{\delta \rho}{\rho_{0}} g$, the reduced gravity and $\rho_{0}$, the reference density. To derive an equation for the relative vorticity, we take $\frac{\partial}{\partial x}(4)-\frac{\partial}{\partial y}(3)$ and obtain: 

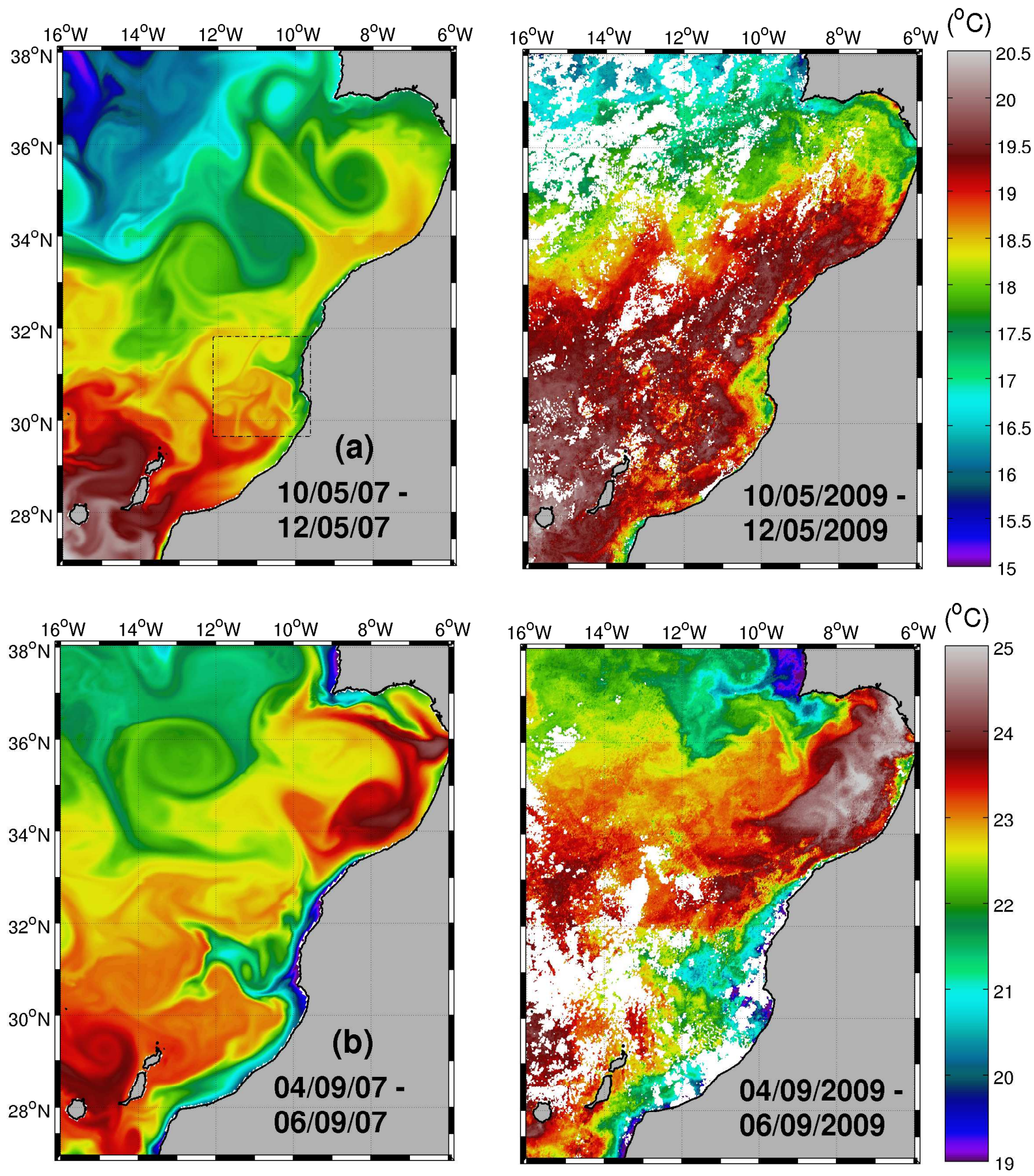

Figure 4: Model (left) and satellite (right) sea surface temperature averaged from 10 to 12 May (a) and from 4 to 6 September (b). $\mathcal{D}_{3}$ solution (dashed square) is superimposed on $\mathcal{D}_{2}$ solution. Model solutions correspond to the last year of run ( 7 th year for $\mathcal{D}_{2}$, 4th year for $\mathcal{D}_{3}$ ). 

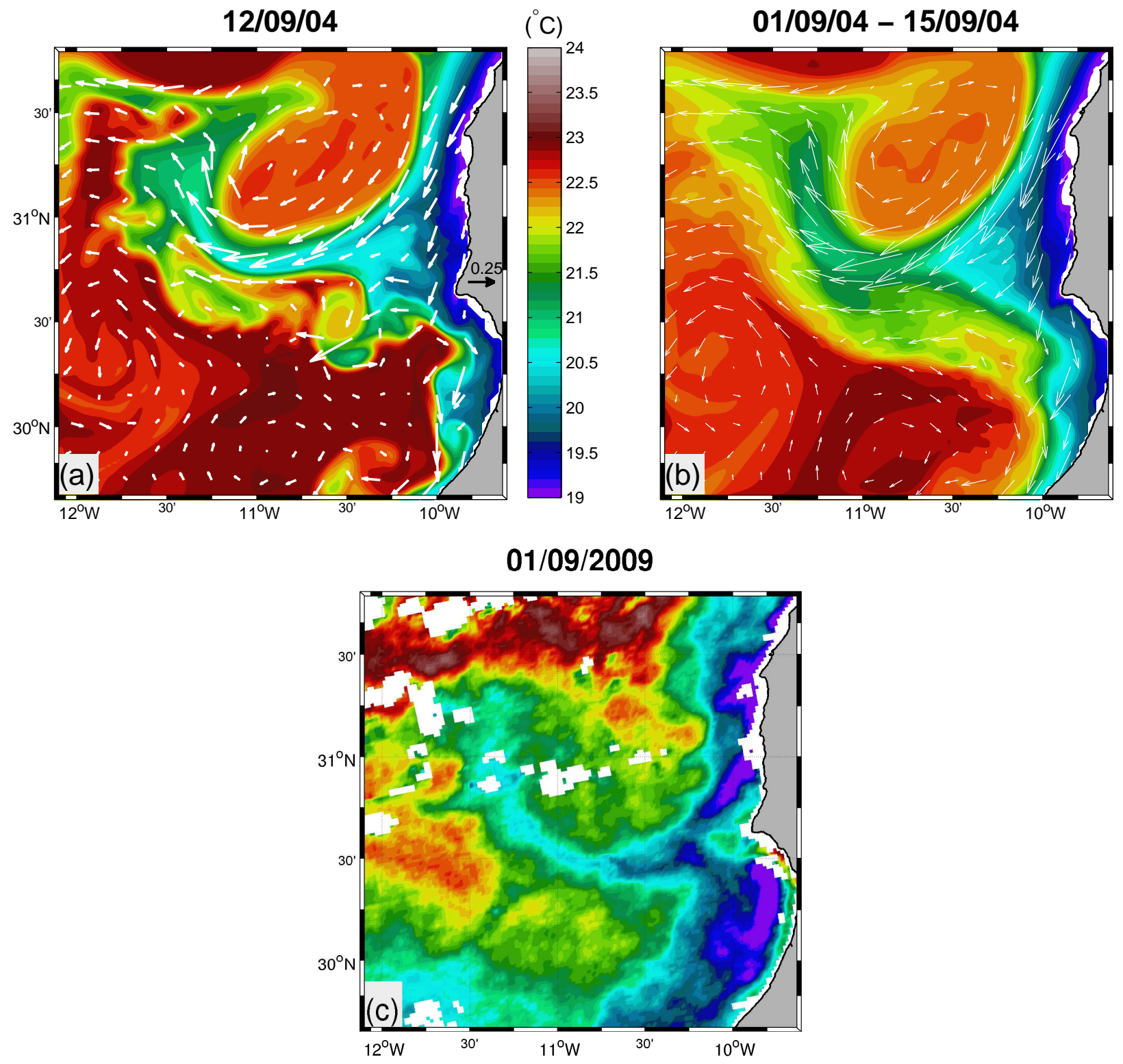

Figure 5: Snapshot of the SST on September 12 (a) and 15-day averaged SST (1-15 September) (b) obtained during the 4th year of simulation in $\mathcal{D}_{3}$ and composite produced from AVHRR measurements on September 1, 2009 (c). 

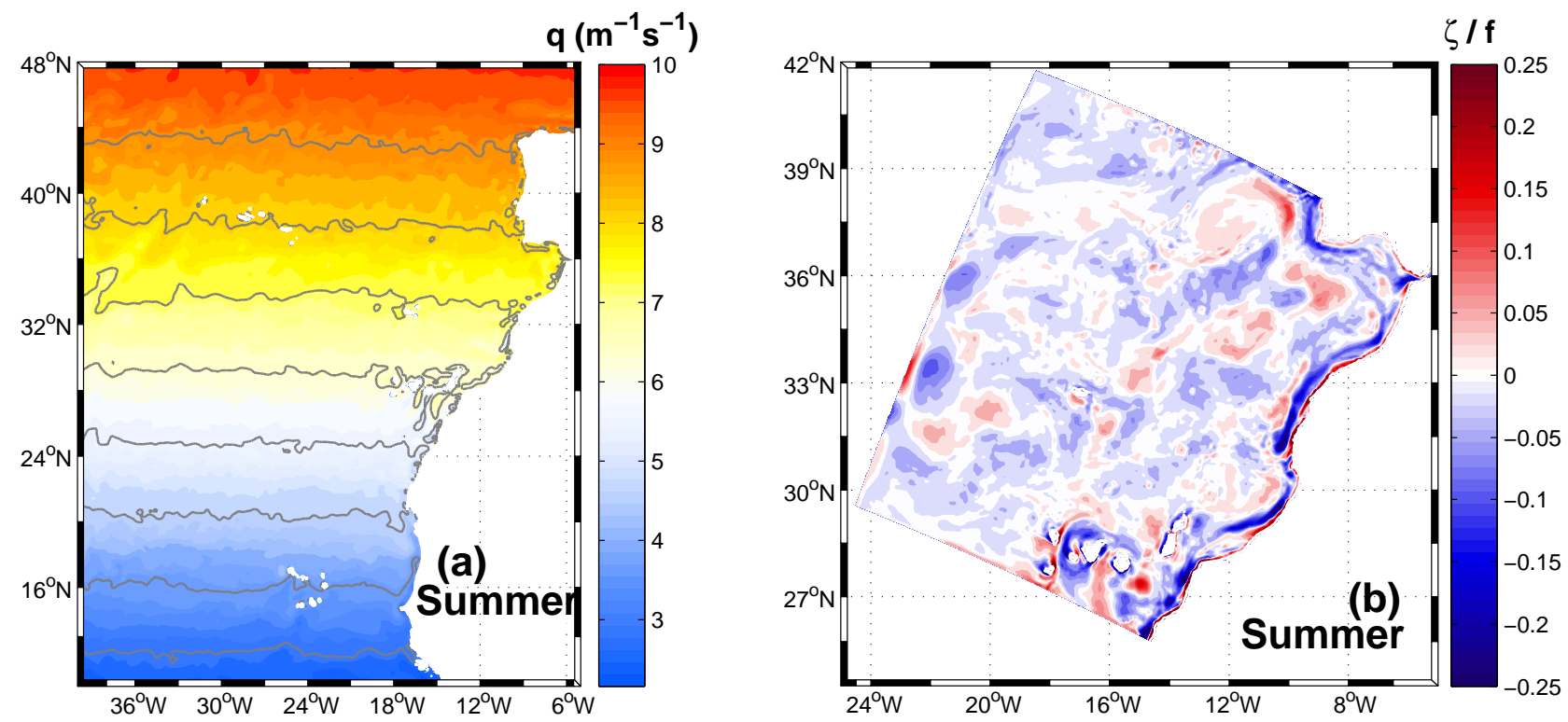

Figure 6: Potential vorticity (normalized by $10^{-6}$ ) in summer for domains $\mathcal{D}_{1}$ (a) and relative vorticity (normalized by $f$ ) in domain $\mathcal{D}_{2}$ (b). PV-lines are separated by $10^{-6} \mathrm{~m}^{-1} \mathrm{~s}^{-1}$.

$$
\frac{\partial \zeta}{\partial t}+\left(u \frac{\partial}{\partial x}+v \frac{\partial}{\partial} y\right) \zeta=\frac{1}{\rho_{0}} \underbrace{\left[\frac{\partial}{\partial x}\left(\frac{\tau^{y}}{h}\right)-\frac{\partial}{\partial y}\left(\frac{\tau^{x}}{h}\right)\right]}_{(*)},
$$

where $\zeta=\frac{\partial v}{\partial x}-\frac{\partial u}{\partial y}$ is the vertical component of the relative vorticity.

The term $(*)$ can be rewritten into:

$$
\begin{aligned}
(*) & =\frac{\partial}{\partial x}\left(\frac{\tau^{y}}{h}\right)-\frac{\partial}{\partial y}\left(\frac{\tau^{x}}{h}\right) \\
& =\frac{1}{h} \frac{\partial \tau^{y}}{\partial x}-\frac{\tau^{y}}{h^{2}} \frac{\partial h}{\partial x}-\frac{1}{h} \frac{\partial \tau^{x}}{\partial y}+\frac{\tau^{x}}{h^{2}} \frac{\partial h}{\partial y} \\
& =\frac{1}{h}[\underbrace{\left(\partial \frac{\tau^{y}}{\partial x}-\frac{\partial \tau^{x}}{\partial y}\right)}_{(* *)}+\underbrace{\left(\frac{\tau^{x}}{h} \frac{\partial h}{\partial y}-\frac{\tau^{y}}{h} \frac{\partial h}{\partial x}\right)}_{(* * *)}]
\end{aligned}
$$

Similarly to Lee et al. (2001), we define the terms $(* *)$ as the torque acting over the surface of the water column and $(* * *)$ as the slope-induced torque: $\tau / h$ represents a volume force applied on the whole water column, of which the effect depends on the slope.

In the studied region, filaments have typical lifetime of a few days, velocity between $0.1-1 \mathrm{~m} \mathrm{~s}^{-1}$, a length of a few hundred kilometers, a width of a few ten kilometers and a depth of a few hundred meters (e.g. Kostianoy and Zatsepin, 1996; Barton et al., 1998; Peliz et al., 2002; Pelegrí et al., 2005). The wind stress curl is estimated from the SCOW climatology (Section 2.2). Using the typical dimensions of the filament, we have:

$$
(* *)=\frac{1}{\rho_{0} h}\left(\frac{\partial \tau^{y}}{\partial x}-\frac{\partial \tau^{x}}{\partial y}\right)=O\left(10^{-9}-10^{-10}\right) s^{-2} .
$$

The zonal variations of depth dominates the meridional variations $(\partial h / \partial x \ll \partial h / \partial y)$, and the wind stress is about one order of magnitude stronger in the meridional direction than in the zonal one $\left(\tau^{y}=O\left(10^{-1}\right) \mathrm{N} / \mathrm{m}^{2}\right)$. With these simplifications, the slope-induced stress is recast into:

$$
(* * *) \approx-\frac{\tau^{y}}{\rho_{0} h^{2}} \frac{\partial h}{\partial x} .
$$

The slope $\partial h / \partial x$ is replaced by $\Delta h / \Delta x$, where $\Delta h$ is the variation of depth when crossing the shelf off Cape Ghir: on the shelf, $h$ is the real depth (topography), while offshore, $h$ the surface layer thickness. In this case, the isopycnal $27.3 \mathrm{~kg} / \mathrm{m}^{3}$ is selected as an indicator of the surface layer. For this isopycnal, the model diagnostics indicate a depth around $250 \mathrm{~m}$ near to the coast, while further offshore, it is almost uniform with values around $150 \mathrm{~m}$. Note that in the first $50 \mathrm{~km}$ from the coast, the depth of the isopycnal $27.3 \mathrm{~kg} / \mathrm{m}^{3}$ is not defined, since all the densities are lower in this area. Based on these values, the slope is estimated as:

$$
\frac{\partial h}{\partial x} \approx \frac{\Delta h}{\Delta x} \approx \frac{100 m}{10 \mathrm{~km}}=10^{-2}
$$

and

$$
\frac{\tau^{y}}{\rho_{0} h^{2}} \frac{\partial h}{\partial x}=\frac{10^{-1}}{10^{3} 10^{4}} 10^{-2}=O\left(10^{-10}\right) s^{-2} .
$$

We conclude that:

- The variations of PV felt by the flow either by changing its latitude, or by increasing the depth of the layer, can be balanced by the relative vorticity provided by the wind.

- Both the wind stress curl and the slope-induced torque contribute to the injection of relative vorticity in the jet, but with a predominance of the wind stress curl. 


\subsection{Procedure}

In the next section, a set of numerical experiments performed in the domain $\mathcal{D}_{3}$ is presented. For both experiments, two characteristic variables are selected: temperature and relative vorticity. Temperature is used to describe and compare the signal of the filament, while relative vorticity acts as the main dynamical variable. The fields are extracted at a depth of $10 \mathrm{~m}$, in order to concentrate on the near-surface variability, in agreement with the filament general characteristics.

\section{Process-oriented numerical experiments}

Several numerical experiments were designed in order to demonstrate that the generation of Cape Ghir filament is related to the gradient of planetary vorticity $(\beta$-effect) and to the injection of positive relative vorticity by the wind curl. For these experiments, surface fields averaged over the first two weeks of September of the fourth year of simulation are considered as diagnostics. This period was selected because the filament appear more frequently and the water column is well stratified, so the filament SST signature is stronger. With the averaging of the fields, high-frequency variability is filtered out. It is then easier to show whether or not a coherent filament is generated.

For the process-oriented simulations, only one modification with respect to the baseline configuration (Section 2) is done at a time, similarly to the approach of Batteen et al. (2007). The numerical experiments combine the different forcing conditions and bathymetries described in the following and summarized in Tab. 2.

The baseline experiment (E0) used the reference climatological atmospheric forcing and bathymetry of Section 2. In experiment E1, planetary vorticity is kept uniform over the domain $\mathcal{D}_{3}$, in order to prove that the filament generation is related with the constraint of PV conservation. The wind effects are analyzed in experiments E2-E3, so as to demonstrate that wind curl constitutes the main source of positive relative vorticity. Experiments E4-E5 are centered on the topographic effects.

Table 2: Descriptions of the process-oriented experiments.

\begin{tabular}{clrl}
\hline Exp. & Description & Wind & Bathymetry \\
\hline E0 & Reference & SCOW $\left(1 / 4^{\circ}\right)$ & GEBCO \\
E1 & $\beta$-effect & SCOW $\left(1 / 4^{\circ}\right)$ & GEBCO \\
E2 & Wind curl & Uniform & GEBCO \\
E3 & Wind resolution & COADS $\left(1^{\circ}\right)$ & GEBCO \\
E4 & Topography smoothing & SCOW $\left(1 / 4^{\circ}\right)$ & Smoothed GEBCO \\
E5 & Shelf-slope only & SCOW $\left(1 / 4^{\circ}\right)$ & Flattened GEBCO \\
\hline
\end{tabular}

\subsection{Baseline experiment (EO)}

The results of this experiment were previously presented and validated in Section. 2.4. Here, the attention is centered on the temperature (Fig. 7a) and relative vorticity maps (Fig. 7b) for the first 15 days of September of the fourth year of simulation with $\mathcal{D}_{3}$. These two variables display very similar features. For comparison with the structures observed with the next experiments, the following characteristics define a filament:
1. strong surface temperature gradient $\left(>2^{\circ} \mathrm{C}\right)$,

2. low aspect ratio (length on the order of $100 \mathrm{~km}$, width on the order of $10 \mathrm{~km}$ ),

3. core characterized by strong positive relative vorticity (as shown in Fig. 7b).

This positive relative vorticity is consistent with the hypothesis that the filament is generated because of a local gain of positive relative vorticity preventing the flow from continuing its way southward. Close to the coast, the vorticity is predominantly positive, with maximal values reached near the irregularities of the coastline. The fields presented here are 15-day averages, hence the signal is not as sharp as in daily results. However, even with this averaging, the temperature signature is still clear, meaning that the process is intense and well localized.

\subsection{Planetary vorticity effect (E1)}

A simple experiment to test the hypothesis of vorticity balance presented in Section 3 is to see how the circulation is modified when planetary vorticity is set constant ( $f$-plane) compared to the case where planetary vorticity varies with latitude $(\beta$ plane). Simulating a situation without $\beta$-effect is easily carried out with a numerical model: all the grid points are assigned with a uniform $f$ value, corresponding to the mean latitude of the domain. Now the constraint from Ertel's theorem (1) that the meridional flow must accommodate its relative vorticity to decreasing planetary vorticity values no longer applies and there is no restriction for the equatorward flow, even if there is an injection of positive relative vorticity by the wind.

Temperature (Fig. 7c) shows that coastal upwelling still develops with the same intensity as in E0, but no filament forms near Cape Ghir. The band of positive relative vorticity is visible (Fig. 7d), but there is not clear offshore propagation, in the manner of the baseline experiment. This supports the importance of the vorticity balance to explain the filament formation. These observations are in agreement with the theory of Marshall and Tansley (2001), who demonstrated that $\beta$-effect enhances the separation of the jet from the coast in case of eastern boundary currents.

Near Cape Sim $\left(31^{\circ} 23^{\prime} N\right)$, a weak westward flow develops, with an anticyclonic eddy north of it. However, this feature does not fit with the previous definition of the filament, because of its spatial scale (limited offshore development). It is probably due to an instability of the upwelling jet, provoked by the coastline curvature.

Obviously, modifying the Coriolis frequency $f$ does not only induce changes in the coastal area, but also in the large-scale circulation. Nevertheless, the choice of a very small nested domain around Cape Ghir shall limit the influence of the modification of $f$. This remark remains valid for the other experiments.

\subsection{Wind forcing effects (E2-E3)}

In the EBUS, it was shown that wind curl is a determinant factor in the near-surface dynamics (e.g., Enriquez and Friehe, 1995; Münchow, 2000; Capet et al., 2004; Castelao and Barth, 
(a) Reference

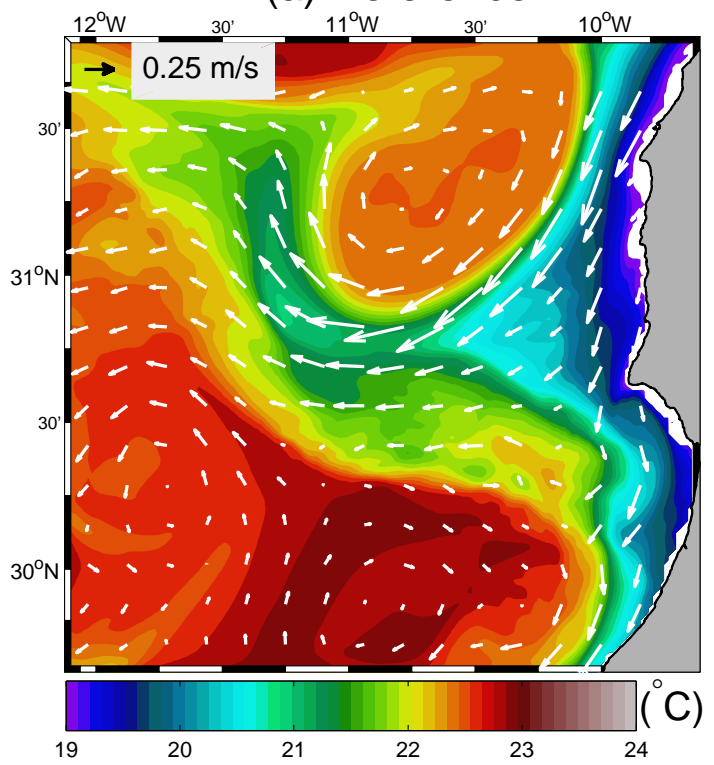

(c) No $\beta$ effect

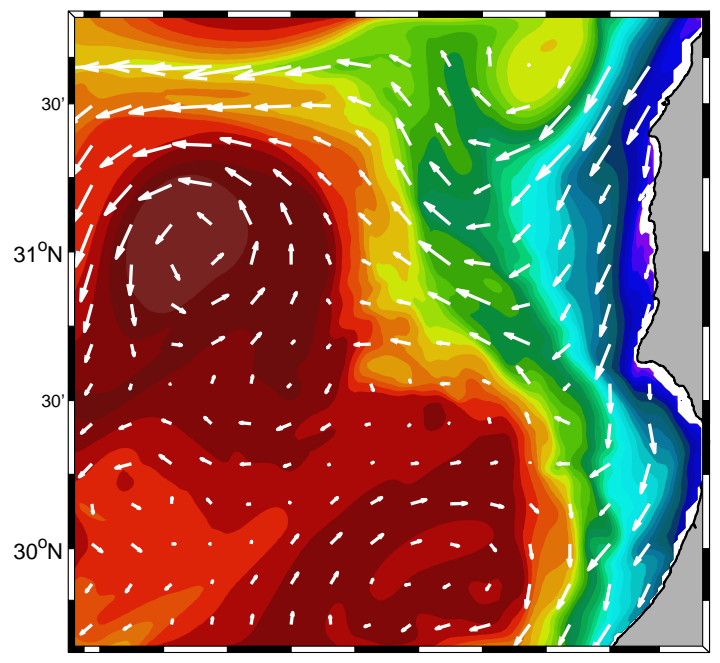

(e) Uniform wind

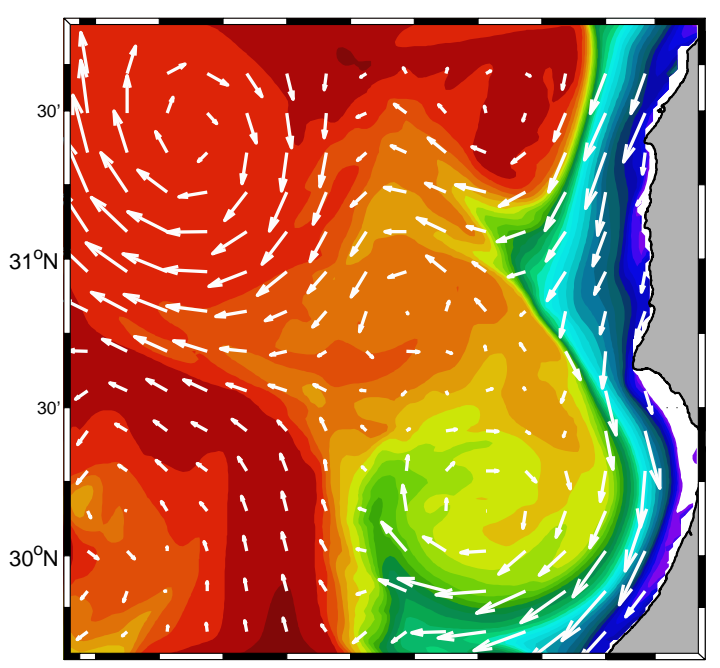

(b)

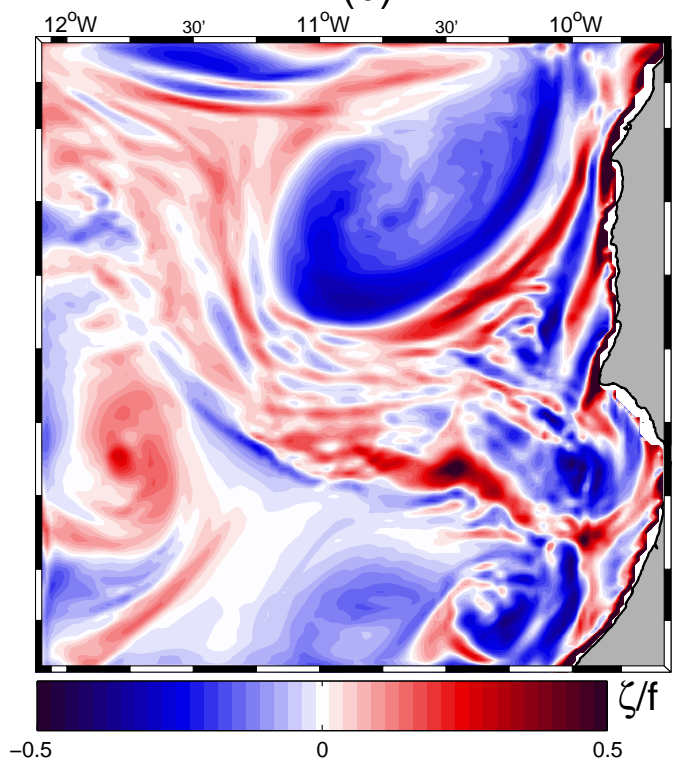

(d)

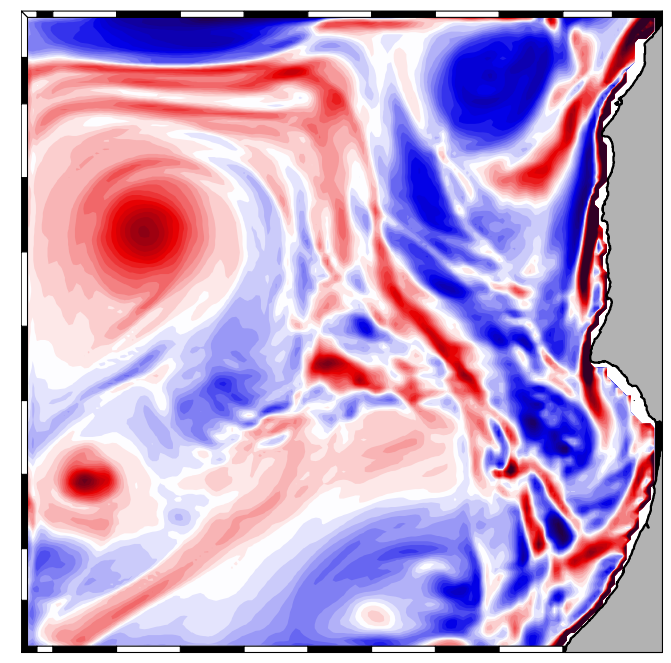

(f)

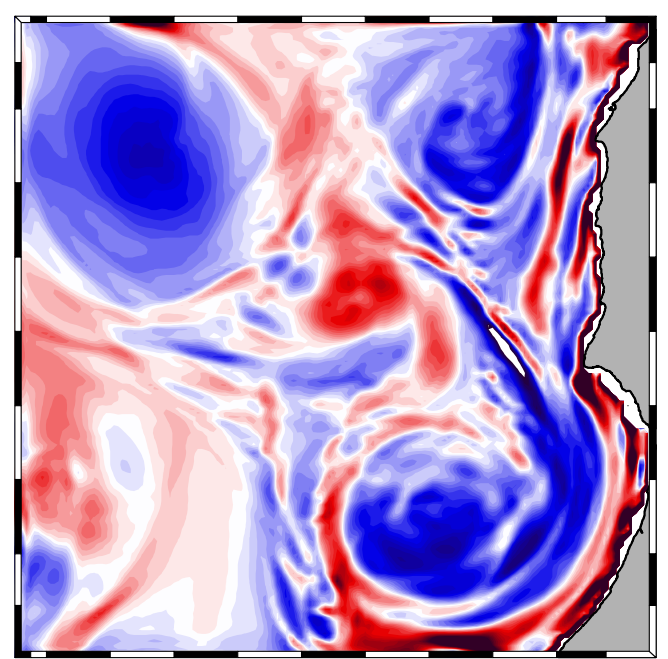

Figure 7: Temperature and velocity field (left column) and normalized relative vorticity (right column) at $10 \mathrm{~m}$ in domain $\mathcal{D}_{3}$, veraged over the first 15 days of September: (a)-(b) baseline configuration (E0), (c)-(d) No $\beta$-effect (E1), (e)-(f) Uniform wind (E2) 
(g) COADS wind

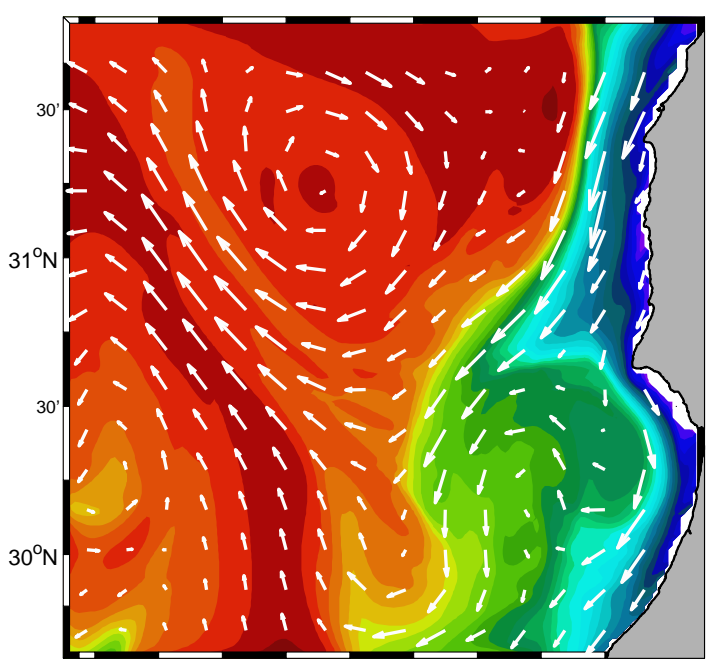

(i) Smoothed bathymetry

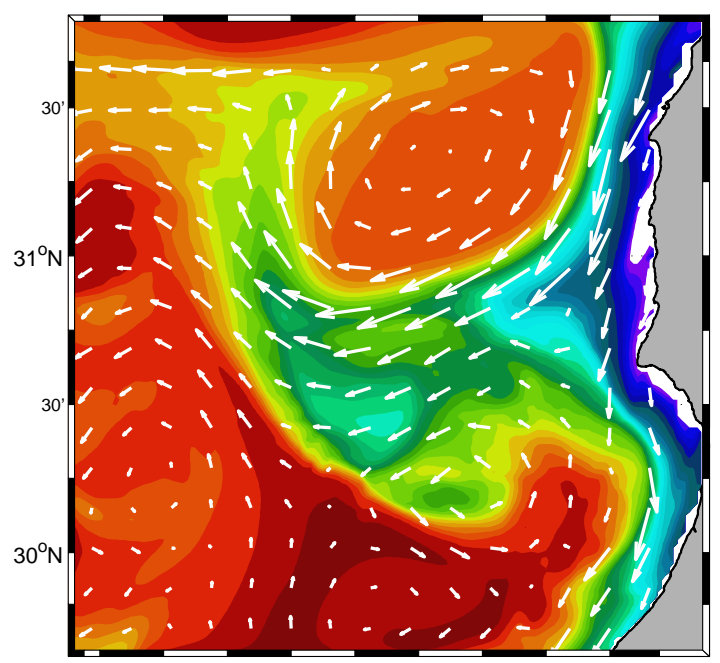

(k) Shelf-slope only

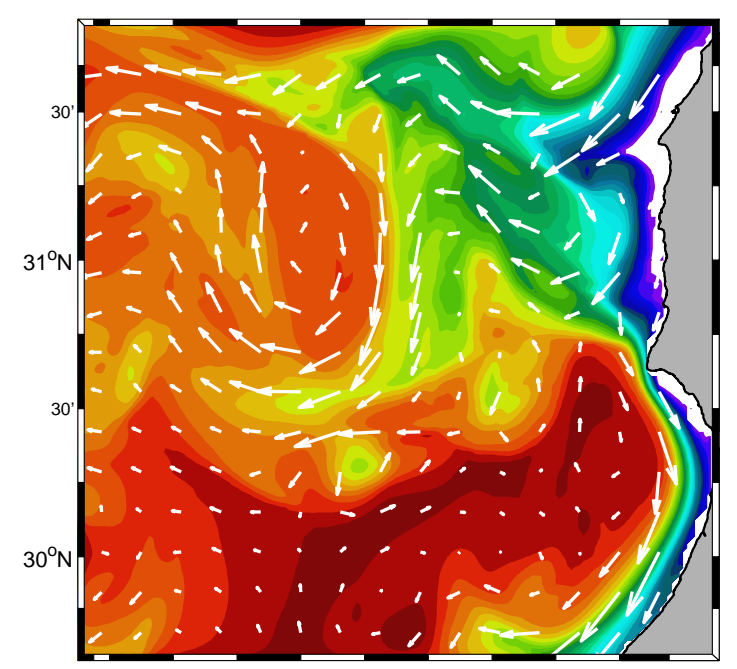

(h)

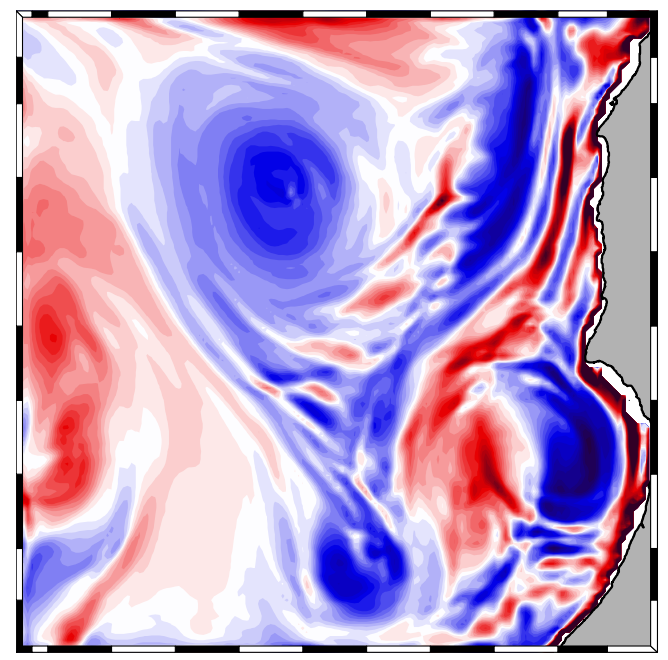

(j)

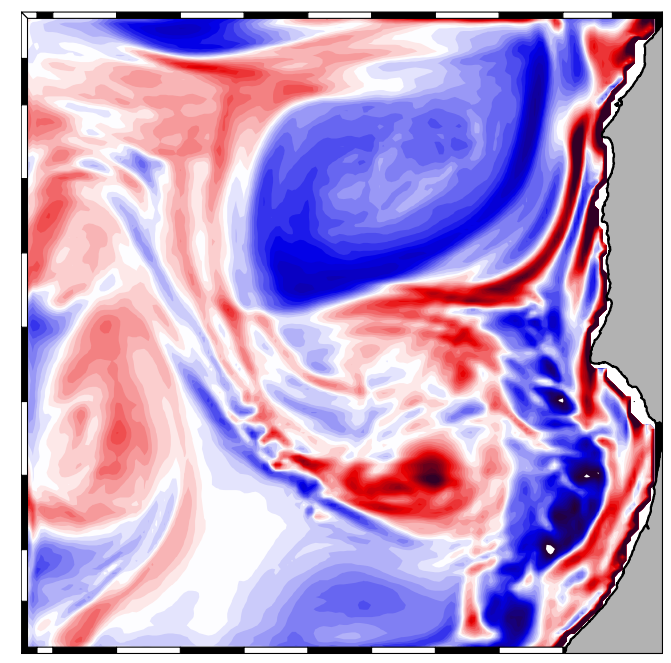

(l)

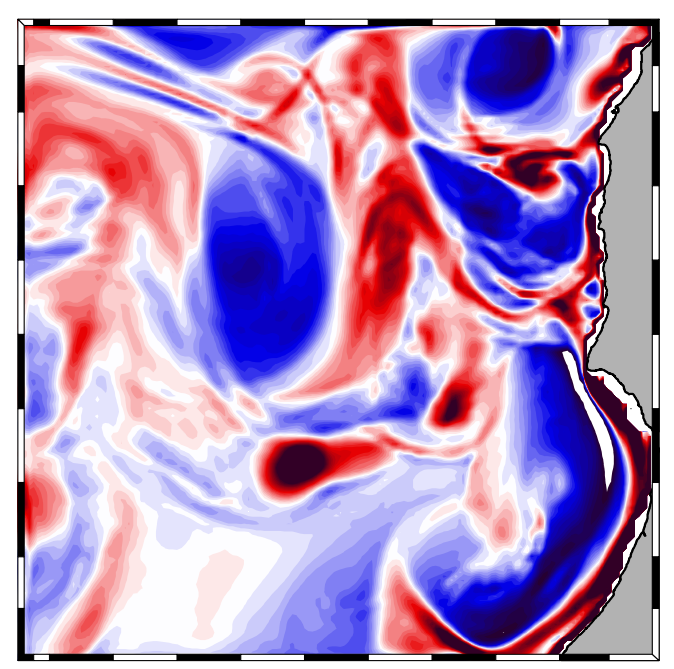

Figure 7: Continued: (g)-(h) COADS wind (E3), (i)-(j) Smoothed topography (E4), (k)-(l) shelf-slope only (E5). 
2007): a positive wind curl creates enhancement of the upwelling (through Ekman pumping) and is responsible for an injection of positive relative vorticity, through squeezing of the water column. Wind stress curls computed in summer using SCOW and COADS wind fields (Fig. 8), are characterized by a band of positive values close to the coast and negative values offshore. This feature is common to the four EBUS (Bakun and Nelson, 1991; Risien and Chelton, 2008).

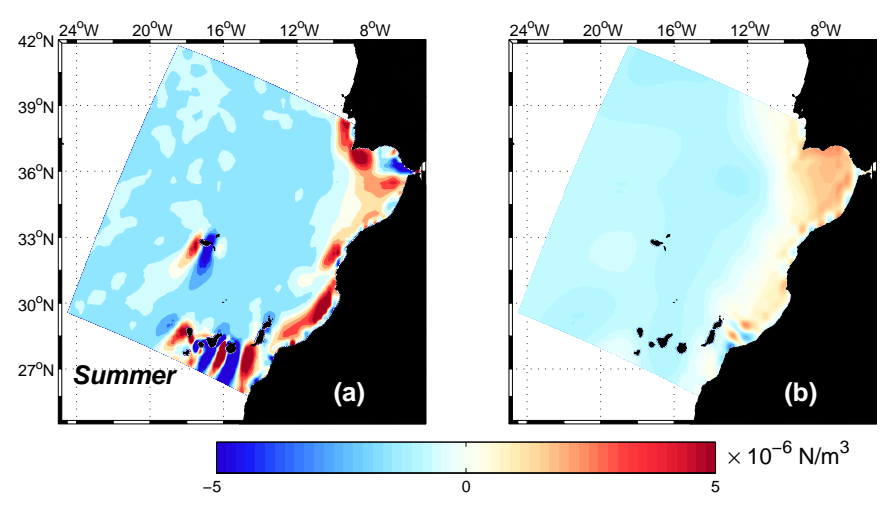

Figure 8: Summer wind stress curl for SCOW (a) and COADS winds (b).

The first wind experiment (E2) consists in working with spatially homogeneous fields. These fields are obtained by spatially averaging the SCOW fields over the domain $\mathcal{D}_{3}$. Doing so, the wind curl effects are removed. The intensity and the direction of this artificial wind field are computed for each month as the spatial averages. The resulting wind direction is still favorable to coastal upwelling (equatorward), but the injection of positive relative vorticity does not take place anymore.

Again, the upwelling characteristics (width and temperature gradient) are comparable to the baseline experiment (Fig. 7e-f), meaning that the general circulation is not strongly perturbed. The main difference is the absence of the filament between Cape Ghir and Cape Sim: the jet tends to follow the isobaths except at $31^{\circ} \mathrm{N}$, where a slight deflection takes place. The relative vorticity map shows that the largest values appear near the coast, particularly close to the capes. The difference with the baseline experiment is that none of the bands of positive vorticity is able to detach from the coastal jet and propagate offshore.

These results underline the role of wind through its curl in the generation of the Cape Ghir filament: when the curl is null, no additional relative vorticity is added to the flow, which can continue its way south.

In the second wind experiment, fields extracted from COADS are considered. The spatial resolution of these wind fields is lower than that of SCOW. The differences are evident when comparing the fields in Fig. 2: COADS fields do not capture the area of accelerated winds centered at $31^{\circ} \mathrm{N}$ close to the coast, nor leeward of the Canary Islands. The area of calm winds south of Cape Ghir is visible in summer, though the contrast with offshore winds is very weak. The annual cycle for SCOW and COADS are generally close, except for January and June: COADS averaged values are much weaker than SCOW ones. Concerning the wind curl, large differences are identified for the width and the intensity of the positive wind-curl band (Fig. 8b): with COADS winds, positive values extend more offshore than with SCOW, but do not exceed $0.5 \times 10^{-6} \mathrm{~N} / \mathrm{m}^{3}$, about $25 \%$ of the intensity of SCOW wind curl in the coastal area.

The results (Fig. 7g) show the development of a westward jet near $31^{\circ} 30^{\prime} \mathrm{N}$, but the typical filament structure does not appear. The jet turns southward at the same latitude as Cape Ghir. The relative vorticity plot (Fig. $7 \mathrm{~h}$ ) displays the detachment of the positive relative vorticity band north of Cape Ghir as well as the anticyclonic eddy centered at $31^{\circ} 15^{\prime} \mathrm{N}$. Even if no filament is produced, there seems to be a trigger effect: the jet starts to turn offshore, but cannot follow the westward direction. The trigger can be reasonably attributed to the interactions of the flow with the topography.

Although this experiment does not bring direct insight into the filament dynamics, it highlights the necessity of a wind forcing with a sufficient spatial resolution in order to reproduce the main filament features.

\subsection{Topographic effects}

In order to assess the role of the bathymetry, some modifications are made on the original one (Fig. 9a). The Cape Ghir Plateau (Fig. 1) constitutes an obstacle for the upwelling jet and consequently it is able to modify the direction of the flow. In order to evaluate the role of the CGP, the $r$-ratio is further reduced ( $r=0.05$ instead of $r=0.20$ ) by the application of a smoothing filter. The corresponding bathymetry is represented in Fig. 9(b). The biggest changes are localized close to the coast (around $50 \mathrm{~km}$ offshore), whereas the differences offshore are negligible.

The resulting temperature and vorticity fields are plotted in Fig. 7(i)-(j). Only a difference of intensity can be observed where the filament turns northward, near $11^{\circ} 20^{\prime} \mathrm{W}$ : temperature is higher than in the baseline experiment. Despite these modifications, the filament remains very similar in both cases. Even if it is involved in the generation mechanism, the topography does not appear to have an influence as strong as the wind field. In a recent study, Meunier et al. (2010) attributed the filament formation only to the interaction of the upwelling current with a promontory on the sea floor. However, as their wind field was uniform, they could not assess their role on the vorticity injection.

The last experiment conducted with the topography employs a shelf-slope only bathymetry, constructed this way: a hyperbolic tangent transformation is applied to the original depths, so that the maximal depth is set to $500 \mathrm{~m}$ and the minimal depth to $50 \mathrm{~m}$. The hyperbolic function allows a smooth transition between the $500 \mathrm{~m}$ and $50 \mathrm{~m}$-deep regions (Fig. 9c).

In this case, the differences with the original bathymetry are significant both near-shore and offshore. With these conditions, the model was able to reproduce the typical features of the filament, except its position, which is about $50 \mathrm{~km}$ north of what is normally observed (Fig. 7k-1). The absence of the CGP certainly plays an essential role: in the results of E0, the filament 

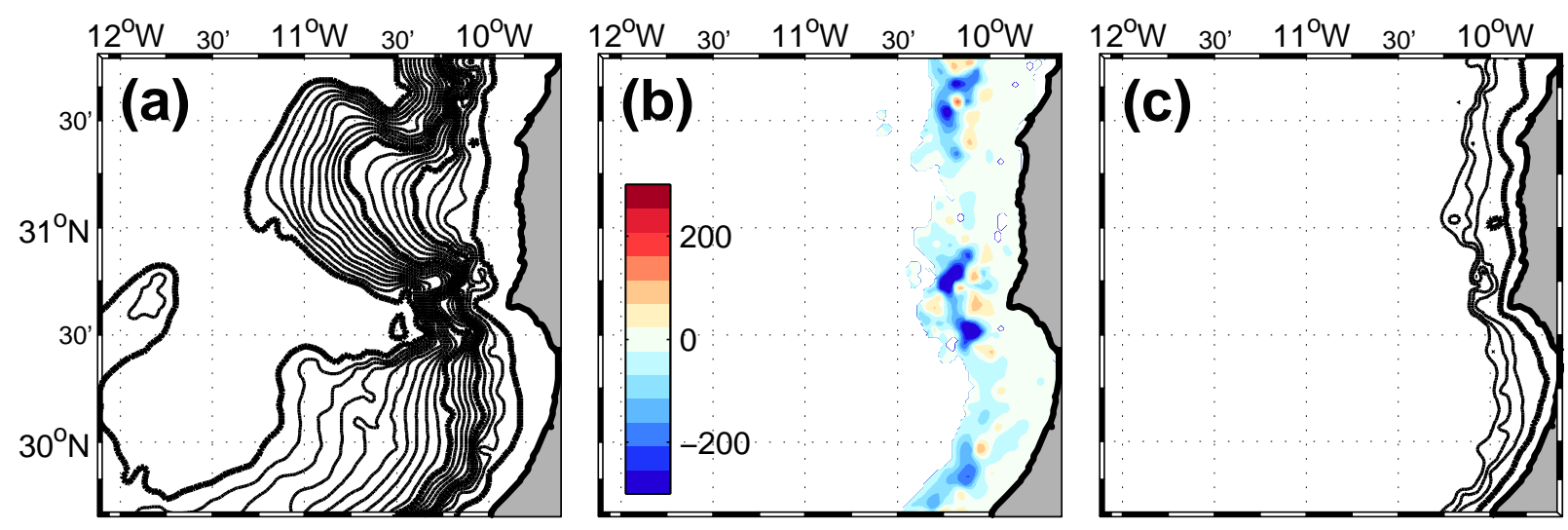

Figure 9: Original model bathymetry (a), difference between over-smoothed and original bathymetries (b) and shelf-slope only bathymetry (c). Thin lines are separated by $100 \mathrm{~m}$, while thick lines represent isobaths $100,500,1000$ and $2000 \mathrm{~m}$.

was flowing just south of this topographic feature. The reason why the filament uprise at a location more at the north is again interpreted in terms of PV conservation: in the region covered by the upwelling jet, the bathymetry underwent a decrease of the bottom depth (absolute value) with respect to the original one. Then the water column is vertically squeezed, and the vorticity balance requires the development of an anticyclonic motion, leading to the formation of a filament.

Modifying the minimum depth (set to $25 \mathrm{~m}$ ) will affect the bottom friction and change the behavior of the relative vorticity in the inner shelf region. However, this will only affect a very narrow region when compared to the whole domain, so that this effect will be local and not affecting qualitatively the domainscale balance of potential vorticity.

The conclusion from these topography-related experiments, is that the Cape Ghir (and its prolongation under sea surface, the CGP), plays the role of a trigger for the filament. The main contribution to the domains-scale balance of potential vorticity is the relative vorticity injected by the wind curl, while the contributions of the bottom torque and related bottom friction are weaker.

\section{Conclusions}

The Cape Ghir filament is a recurrent feature of the Canary Current upwelling system. This study aims at numerically simulating the characteristics of the filaments and examining the mechanisms of generation. Filaments are frequently observed north of Cape Ghir through satellite imagery, but few modeling efforts could accurately represent its location and characteristic dimensions.

The baseline configuration, fed with realistic forcing conditions and boundary conditions from a larger domain, was capable to reproduce the main features of the filament (spatial and temporal scales, temperature gradient, location) with a good degree of realism. The spatial resolution $(1.5 \mathrm{~km})$ proves to be sufficient for the objective of our study. In another work in progress, a set of experiments was run with a finer horizontal resolution $(800 \mathrm{~m})$. The results were quite similar concerning the general filament dynamics, while frontal instabilities developed along the filament edges. These instabilities may play a role in the dissipation of the filament and in the transfer of water properties, but are not expected to influence the mechanism of formation.

The different experiments focused on the mechanisms of generation were defined by modifying the conditions of the baseline experiment. They were designed to assess the role of wind, geometry (bottom and coastline) and planetary vorticity on the dynamics of the filament. The proposed mechanism is based on the conservation of PV within the upwelling jet. The experiment with the uniform $f$ parameter (no $\beta$-effect) did not produce any filament, as the restriction of an equatorward flow was eliminated. This confirms the validity of the vorticity balance assumption, even if such a condition on the Coriolis frequency is not feasible in reality.

The experiments dedicated to the wind effects (E2-E3) underline its role on the filament formation, through the injection of positive relative vorticity into the flow. In the uniform wind experiment (E2), the injection of vorticity by the wind is removed. According to the proposed mechanism (Section 3), since the jet did not receive relative vorticity, it continued its way along the coast. When interpolated onto the model grid, COADS winds (E3) display a wider but weaker band of positive wind curl along the coast of NW Africa. It results in a flow without any filament during the studied period, although some meandering of the jet is observed north of Cape Ghir.

The bathymetry is considered as a trigger to the filament formation: numerous observational studies confirm that their location is related to the coast irregularities. When the bathymetry is slightly modified (E4), the resulting fields are still very close to the reference case, meaning that filament formation is not strongly sensitive to the variation in the bathymetry. In this experiment, the trigger effect of Cape Ghir is slightly affected, hence the same wind field creates a filament at the same location. It is probable that once the filament has been generated, its trajectory is more dependent on the topographic features of the bottom. When the sea floor is made flat, except in the vicinity of the coast, a filament is still produced, but a location that 
does not correspond to real observations. This discrepancy is again explained by effects on the PV. We conclude that a realistic bathymetry is necessary to achieve to trigger the filament detachment at the correct location, even if the sensitivity to this parameter is much lower than to wind.

From these experiments, it is believed that the key ingredient to better resolve the filament dynamics is the interactions between wind and topography: Cape Ghir is not only a coastal geographical feature, but has continuation below (the CGP) and above sea surface (High Atlas range). The general direction and intensity of the wind is modified at the latitude of Cape Ghir (Fig. 2). The coupling with an atmospheric model would certainly give a better insight of the role of wind and relate its intensity to the land relief.

The wind spatial resolution appears as a essential issue: Real observations indicate that, within an area of a few tenths of $\mathrm{km}$ offshore, wind intensity tends to diminish when approaching the coast (e.g., in California, Dorman et al., 2006). This dropoff is not properly represented with a resolution of $0.25^{\circ}$. Yet it certainly plays a role in the filament dynamics, through an additional generation of positive wind stress curl and an influence on the upwelling intensity (Enriquez and Friehe, 1995; Capet et al., 2004; Dever et al., 2006).

The application of the same methodology (climatological run and modified conditions) to the other filaments in the Canary Current System (e.g., Cape Blanc, Cape Bajador, Cape Saint Vincent) or in another EBUS would allow one to determine if the proposed mechanism is generally applicable, or typical of Cape Ghir. Of particular interest are the California Current System and the Iberian Peninsula, where wind is favorable to upwelling all year long.

\section{Acknowledgments}

The authors thank J. Molemaker and F. Colas for their suggestions on the preparation of the simulations, A. Barth and F. Lenartz for their numerous remarks on a first version of the manuscript, I. Laiz for her contribution to the mechanism and G. Pop for his help with the cluster used to run the model. Comments by two anonymous reviewers greatly improved the manuscript.

This work was facilitated by a Subside Fédéral pour la Recherche (Belgium) and a travel grant from the French Community of Belgium. The support from the Fonds pour la Formation à la Recherche dans l'Industrie et dans l'Agriculture (FRIA) is greatly appreciated, as well as contributions from the Spanish MEC through the CAIBEX Project (CTM200766408-C02-01/MAR). E. Mason is supported by the Spanish Government through projects MOC2 (CTM200806438C0201), RODA (CTM200406842CO303) and CAIBEX. Part of this work was written while P. S. was visiting the group of Prof. J. C. McWilliams at Institute of Geophysics and Planetary Physics of the University of California Los Angeles, supported with a scholarship from the Spanish Government (Salvador de Madariaga, PR2010-0517).

\section{References}

Bakun, A.K., Nelson, C.S., 1991. The seasonal cycle of windtress curl in subtropical eastern boundary current regions. Journal of Physical Oceanography 21, 1815-1834. doi:10.1175/15200485(1991)021<1815:TSCOWS > 2.0.CO;2.

Barton, E.D., Arístegui, J., 2004. The Canary Islands Coastal Transition Zone: Upwelling, eddies and filaments. Progress in Oceanography 62, 67-69. doi:10.1016/j.pocean.2004.08.003.

Barton, E.D., Arístegui, J., Tett, P., Cantón, M., García-Braun, J., HernándezLeón, S., Nykjaer, L., Almeida, C., Almunia, J., Ballesteros, S., Basterretxea, G., Escánez, J., García-Weill, L., Hernández-Guerra, A., LópezLaatzen, F., Molina, R., Montero, M.F., Navarro-Pérez, E., Rodríguez, J.M., van Lenning, K., Vélez, H., Wild, K., 1998. The transition zone of the Canary Current upwelling region. Progress in Oceanography 41, 455-504. doi:10.1016/S0079-6611(98)00023-8.

Batteen, M.L., Martinez, J.R., Bryan, D.W., Buch, E.J., 2000. A modeling study of the coastal eastern boundary current system off Iberia and Morocco. Journal of Geophysical Research 105, 14173-14195. doi:10.1029/2000JC900026.

Batteen, M.L., Martinho, A.S., Miller, H.A., McClean, J.L., 2007. A processoriented modelling study of the coastal Canary and Iberian Current system. Ocean Modelling 18, 1-36. doi:10.1016/j.ocemod.2007.02.006.

URL: http://www.sciencedirect.com/science/article/pii/ S1463500307000376

Beardsley, R.C., Lentz, S.J., 1987. The coastal ocean dynamics experiment collection: An introduction. Journal of Geophysical Research 92, 14551463. doi:10.1029/JC092iC02p01455.

Bernstein, R.L., Breaker, L., Whritner, R., 1977. California Current eddy formation: Ship, air, and satellite results. Science 195, 353-359. doi:10.1126/science.195.4276.353.

Blayo, E., Debreu, L., 2005. Revisiting open boundary conditions from the point of view of characteristic variables. Ocean Modelling 9, 231-252. doi:10.1016/j.ocemod.2004.07.001.

URL: http://www.sciencedirect.com/science/article/pii/ S1463500304000447

Brink, K., 1983. The near-surface dynamics of coastal upwelling. Progress in Oceanography 12, 223-257. doi:10.1016/0079-6611(83)90009-5.

Brink, K.H., Cowles, T.J., 1991. The coastal transition zone experiment. Journal of Geophysical Research 96, 14637-14647. doi:10.1029/91JC01206.

Brink, K.H., Stuart, D.W., Van Leer, J.C., 1984. Observations of the coastal upwelling region near $34^{\circ} 30^{\prime} \mathrm{N}$ of California: Spring 1981. Journal of Physical Oceanography 14, 378-391. doi:10.1175/15200485(1984)014<0378:OOTCUR >2.0.CO;2.

Capet, X.J., Marchesiello, P., McWilliams, J.C., 2004. Upwelling response to coastal wind profiles. Geophysical Research Letters 31, L13311. doi:10.1029/2004GL020123.

Castelao, R.M., Barth, J.A., 2007. The role of wind stress curl in jet separation at a cape. Journal of Physical Oceanography 37, 2652-2671. doi:10.1175/2007JPO3679.1.

Dever, E.P., Dorman, C.E., Largier, J.L., 2006. Surface boundary-layer variability off Northern California, USA, during upwelling. Deep-Sea Research II 53, 2887-2905. doi:10.1016/j.dsr2.2006.09.001.

Dickinson, R.E., 1978. Rossby waves - Long-period oscillations of oceans and atmospheres. Annual Review of Fluid Mechanics 10, 159-195. doi:10.1146/annurev.fl.10.010178.001111.

Dorman, C.E., Dever, E.P., Largier, J., Koracin, D., 2006. Buoy measured wind, wind stress and wind stress curl over the shelf off Bodega Bay, California. Deep-Sea Research II 53, 2850-2864. doi:10.1016/j.dsr2.2006.07.006.

Durand, M.H., Cury, P., Mendelssohn, R., Roy, C., Bakun, A., Pauly, D. (Eds.), 1998. Global versus Local Changes in Upwelling Systems. ORSTOM, Paris. ISBN 2-7099-1389-5.

Durski, S.M., Allen, J.S., 2005. Finite-amplitude evolution of instabilities associated with the coastal upwelling front. Journal of Physical Oceanography 35, 1606-1628. doi:10.1175/JPO2762.1. URL: http://journals .ametsoc .org/doi/abs/10.1175/JP02762 . 1

Durski, S.M., Allen, J.S., Egbert, G.D., Samelson, R.M., 2007. Scale evolution of finite-amplitude instabilities on a coastal upwelling front. Journal of Physical Oceanography 37, 837-854. doi:10.1175/JPO2994.1. URL: http://journals . ametsoc .org/doi/abs/10.1175/JP02994. 1 
Durski, S.M., Samelson, R.M., Allen, J.S., Egbert, G.D., 2008. Normal-mode instabilities of a time-dependent coastal upwelling jet. Journal of Physical Oceanography 38, 2056-2071. doi:10.1175/2008JPO3803.1.

URL: http://journals.ametsoc.org/doi/abs/10.1175/ 2008JP03803.1

Enriquez, A.G., Friehe, C.A., 1995. Effects of wind stress and wind stress curl variability on coastal upwelling. Journal of Physical Oceanography 25, 1651-1671. doi:10.1175/15200485(1995)025<1651:EOWSAW>2.0.CO;2.

Flament, P., 1985. The evolving structure of an upwelling filament. Journal of Geophysical Research 90, 11765-11778. doi:10.1029/JC090iC06p11765.

Gabric, A.J., Garcia, L., van Camp, L., Nykjaer, L., Eifler, W., Schrimpf, W., 1993. Offshore export of shelf production in the Cap Blanc giant filament as derived from Coastal Zone Color Scanner imagery. Journal of Geophysical Research 98, 4697-4712. doi:10.1029/92JC01714.

García-Weill, L., Nykjaer, L., Tejera-Cruz, A., Cantón, M., 1994. Cálculo de velocidades oceánicas superficiales en el área del afloramiento del NW de África mediante imágenes del sensor AVHRR. Revista de Teledetección 3, 37-41.

Hagen, E., 2005. Zonal wavelengths of planetary Rossby waves derived from hydrographic transects in the Northeast Atlantic Ocean? Journal of Oceanography 61, 1039-1046. doi:10.1007/s10872-006-0020-3.

URL: http://www.springerlink. com/content/ 10752144p2j6q237/

Hagen, E., Zülicke, C., Feistal, R., 1996. Near surface structures in the Cape Ghir filament off Morocco. Oceanologica Acta 19, 577-598.

Haynes, R., Barton, E.D., Pilling, I., 1993. Development, persistence and variability of upwelling filaments off the Atlantic Coast of the Iberian Peninsula. Journal of Geophysical Research 98, 22681-22692. doi: $10.1029 / 93 \mathrm{JC} 02016$.

Hernández-Guerra, A., Nykjaer, L., 1997. Sea surface temperature variability off North-West Africa: 1981-1989. International Journal of Remote Sensing 18, 2539-2558. doi:10.1080/014311697217468.

Hunter, P., Macnab, R., 2003. The GEBCO Digital Atlas published by the British Oceanographic Data Centre on behalf of IOC and IHO. North Atlantic region .

URL: http://www.gebco.net/

Huyer, A., Barth, J.A., Kosro, P.M., Shearman, R.K., Smith, R.L., 1998. Upperocean water mass characteristics of the California Current, summer 1993 Deep-Sea Research II 45, 1411-1442. doi:10.1016/S0967-0645(98)800027.

Ikeda, M., Emery, W.J., 1984. Satellite observations and modeling of meanders in the California Current system off Oregon and Northern California. Journal of Physical Oceanography 14, 1434-1450. doi:10.1175/15200485(1984)014<1434:SOAMOM>2.0.CO;2.

Jennings, S., Kaiser, M., Reynolds, J.D., 2001. Marine Fisheries Ecology. Blackwell Science Ltd, Oxford. ISBN 978-0-632-05098-7.

Johnson, J., Stevens, I., 2000. A fine resolution model of the eastern North Atlantic between the Azores, the Canary Islands and the Gibraltar Strait. Deep-Sea Research I 47, 875-899. doi:10.1016/S0967-0637(99)00073-4.

Karakas, G., Nowald, N., Blaas, M., Marchesiello, P., Frickenhaus, S. Schlitzer, R., 2006. High-resolution modeling of sediment erosion and particle transport across the northwest African shelf. Journal of Geophysical Research 111, C06025 1-13. doi:10.1029/2005JC003296.

Kelly, K., 1986. The influence of winds and topography on sea surface temperature patterns over the Northern California slope. Journal of Geophysical Research 90, 11783-11798. doi:10.1029/JC090iC06p11783.

Kosro, P.M., Huyer, A., 1986. CTD and velocity surveys of seaward jets off northern California, July 1981 and 1982. Journal of Geophysical Research 91, 7680-7690. doi:10.1029/91JC00885.

Kostianoy, A.G., Zatsepin, A.G., 1996. The West African coastal upwelling filaments and cross-frontal water exchange conditioned by them. Journal of Marine Systems 7, 349-359. doi:10.1016/0924-7963(95)00029-1.

Laiz, I., Sangrà, P., Pelegrí, J.L., Marrero-Díaz, A., 2001. Sensitivity of an idealised subtropical gyre to the eastern boundary conditions. Scientia Marina 65, 187-194. doi:10.3989/scimar.2001.65s1187.

Lee, S.K., Pelegrí, J.L., Kroll, J., 2001. Slope control in western boundary currents. Journal of Physical Oceanography 31, 3349-3360. doi:10.1175/15200485(2001) $031<3349$ : SCIWBC $>2.0$.CO 2 .

Lutjeharms, J.R.E., Shillington, F.A., Duncombe Rae, C.M., 1991. Observations of extreme upwelling filaments in the Southeast Atlantic Ocean. Sci- ence 253, 774-776. doi:10.1126/science.253.5021.774.

Marshall, D.P., Tansley, C.E., 2001. An implicit formula for boundary current separation. Journal of Physical Oceanography 31, 1633-1638. doi:10.1175/1520-0485(2001)031<1633:AIFFBC >2.0.CO;2.

Martinho, A.S., Batteen, M.L., 2006. On reducing the slope parameter in terrain-following numerical ocean models. Ocean Modelling 13, 166-175. doi:10.1016/j.ocemod.2006.01.003

URL: http://www.sciencedirect.com/science/article/pii/ S1463500306000060

Mason, E., Colas, F., Molemaker, J., Shchepetkin, A., Sangrà, P., McWilliams, J., 2008. Seasonal variability of the Canary Current System. in: Eastern Boundary Upwelling Ecosystems, Las Palmas de Gran Canaria, Spain.

Mason, E., Colas, F., Molemaker, J., Shchepetkin, A.F., Troupin, C., McWilliams, J.C., Sangrà, P., 2011. Seasonal variability of the Canary Current: a numerical study. Journal of Geophysical Research 116, C06001. doi:10.1029/2010JC006665

URL: http://www.agu.org/journals/jc/jc1106/2010JC006665/ 2010JC006665.pdf

Mason, E., Molemaker, J., Shchepetkin, A.F., Colas, F., McWilliams, J.C., Sangrà, P., 2010. Procedures for offline grid nesting in regional ocean models. Ocean Modelling 35, 1-15. doi:10.1016/j.ocemod.2010.05.007.

Meunier, T., Rossi, V., Morel, Y., Carton, X., 2010. Influence of bottom topography on an upwelling current: Generation of long trapped filaments. Ocean Modelling 35, 277-303. doi:10.1016/j.ocemod.2010.08.004. URL: http://www.sciencedirect.com/science/article/ B6VPS-50W1TPD-2/2/eac751cd6591c014f49603f2dea97c87

Mooers, C.N.K., Robinson, A.R., 1984. Turbulent jets and eddies in the California Current and inferred cross-shore transports. Science 223, 51-53. doi:10.1126/science.223.4631.51.

Müller, P., 1995. Ertel's potential vorticity theorem in physical oceanography. Reviews of Geophysics 33, 67-97. doi:10.1029/94RG03215.

Münchow, A., 2000. Wind stress curl forcing of the coastal ocean near Point Conception, California. Journal of Physical Oceanography 30, 1265-1280. doi:10.1175/1520-0485(2000)030<1265:WSCFOT>2.0.CO;2.

Pedlosky, J., 1987. Geophysical Fluid Dynamics. Springer-Verlag. 2nd edition. ISBN 0-387-96387-1.

Pelegrí, J.L., Marrero-Díaz, A., Ratsimandresy, A., Antoranz, A., CisnerosAguirre, J., Gordo, C., Grisolía, D., Hernández-Guerra, A., Laíz, I., Martínez, A., Parrilla, G., Pérez-Rodríguez, P., Rodríguez-Santana, A., Sangrà, P., 2005. Hydrographic cruises off northwest Africa: the Canary Current and the Cape Ghir region. Journal of Marine Systems 54, 39-63. doi:10.1016/j.jmarsys.2004.07.001

Peliz, A., Rosa, T.L., Santos, A.M.P., Pissarra, J.L., 2002. Fronts, jets, and counter-flows in the Western Iberian upwelling system. Journal of Marine Systems 35, 61-77. doi:10.1016/S0924-7963(02)00076-3.

Peliz, A., Santos, A.M.P., Oliveira, P.B., Dubert, J., 2004. Extreme cross-shelf transport induced by eddy interactions southwest of Iberia in winter 2001. Geophysical Research Letters 31, L08301. doi:10.1029/2004GL019618.

Penven, P., Marchesiello, P., Debreu, L., Lefèvre, J., 2008. Software tools for pre- and post-processing of oceanic regional simulations. Environmental Modelling \& Software 23, 660-662. doi:10.1016/j.envsoft.2007.07.004.

Risien, C.M., Chelton, D.B., 2008. A global climatology of surface wind and wind stress fields from 8 years of QuikSCAT scatterometer data. Journal of Physical Oceanography 38, 2379-2413. doi:10.1175/2008JPO3881.1.

Ryther, J.H., 1969. Photosynthesis and fish production in the sea. Science 166, $72-76$

URL: http: //www.jstor.org/stable/1727735

Shchepetkin, A.F., McWilliams, J.C., 2005. The regional oceanic modeling system (ROMS): a split-explicit, free-surface, topographyfollowing-coordinate oceanic model. Ocean Modelling 9, 347-404. doi:10.1016/j.ocemod.2004.08.002.

Shchepetkin, A.F., McWilliams, J.C., 2009. Correction and commentary for "Ocean forecasting in terrain-following coordinates: Formulation and skill assessment of the regional ocean modeling system" by Haidvogel et al., J. Comp. Phys. 227, pp. 3595-3624. Journal of Computational Physics 228, 8985-9000. doi:10.1016/j.jcp.2009.09.002.

Spall, M.A., 1990. Circulation in the Canary Basin: A model/data analysis. Journal of Geophysical Research 95, 9611-9628. doi:10.1029/JC095iC06p09611.

Stevens, I., Hamann, M., Johnson, J.A., Fiúza, A.F.G., 2000. Comparisons between a fine resolution model and observations in the Iberian shelf- 
slope region. Journal of Marine Systems 26, 53-74. doi:10.1016/S09247963(00)00038-5.

Stevens, I., Johnson, J., 2003. A numerical modelling study of upwelling filaments off the NW African coast. Oceanologica Acta 26, 549-564. doi:10.1016/S0399-1784(03)00049-5.

Stramma, L., 1984. Geostrophic transport in the warm water sphere of the eastern subtropical North Atlantic. Journal of Marine Research 42, 537558. doi:10.1357/002224084788506022.

Stramma, L., Schott, F., 1999. The mean flow field of the tropical Atlantic Ocean. Deep-Sea Research II 46, 279-303. doi:doi:10.1016/S09670645(98)00109-X.

URL: http://www.ingentaconnect.com/content/els/09670645/ 1999/00000046/00000001/art00109

Strub, P.T., Kosro, P.M., Huyer, A., 1991. The nature of cold filaments in the California Current system. Journal of Geophysical Research 96, 1474314768. doi:10.1029/91JC01024.

Troupin, C., Sangrà, P., Arístegui, J., 2010. Seasonal variability of the oceanic upper layer and its modulation of biological cycles in the Canary Island region. Journal of Marine Systems 80, 172-183. doi:10.1016/j.jmarsys.2009.10.007.

Van Camp, L., Nykjaer, L., Mittelstaed, E., Schlittenhard, P., 1991. Upwelling and boundary circulation off Northwest Africa as depicted by infrared and visible satellite observations. Progress in Oceanography 26, 357402. doi:10.1016/0079-6611(91)90012-B.

Woodruf, S.D., Diaz, H.F., Elms, J.D., Worley, S.J., 1998. COADS release 2 data and metadata enhancements for improvements of marine surface flux fields. Physics and Chemistry of the Earth 23, 517-526. doi:10.1016/S00791946(98)00064-0.

Wooster, W.S., Bakun, A., McLain, D.R., 1976. The seasonal upwelling cycle along the eastern boundary of the North Atlantic. Journal of Marine Research 34, 131-140.

Worley, S.J., Woodruff, S.D., Reynolds, R., Lubker, S.J., Lott, N., 2005. ICOADS release 2.1 data and products. International Journal of Climatology 25, 823-842. doi:10.1002/joc.1166. 